\title{
Timing of volcanism along the northern East Pacific Rise based on paleointensity experiments on basaltic glasses
}

\author{
J. Carlut ${ }^{1}$ \\ Laboratoire de Géologie, UMR 8538, CNRS, Ecole Normale Supérieure de Paris, Paris, France \\ M.-H. Cormier, D. V. Kent, ${ }^{2}$ K. E. Donnelly, and C. H. Langmuir ${ }^{3}$ \\ Lamont-Doherty Earth Observatory, Columbia University, Palisades, New York, USA
}

Received 4 July 2003; revised 21 November 2003; accepted 14 January 2004; published 16 April 2004.

[1] Samples from two adjacent and contrasting ridge segments along the East Pacific Rise were measured for their magnetic paleointensity in order to further explore the possibilities of dating very young volcanic samples using secular variations in the Earth's magnetic field. The ridge segment north of the Orozco transform fault $\left(15^{\circ} 22^{\prime}-16^{\circ} 20^{\prime} \mathrm{N}\right)$ is the shallowest and broadest along more than $5000 \mathrm{~km}$ of the East Pacific Rise, whereas the adjacent segment to the north $\left(16^{\circ} 16^{\prime}-18^{\circ} \mathrm{N}\right)$ has a "typical" morphology for its intermediate spreading rate. Both ridge segments were densely sampled during the PANR01MV cruise and 36 samples of axial lava flows, consisting mainly of glasses from the rims of the flows and some fragments of lobate basalts, were selected from this collection for paleointensity experiments. The Coe version of the Thellier double-heating procedure (in air) was used. Twenty-seven units provide internally consistent paleointensity estimates leading to precise estimates of the paleofield, which range between $8 \mu \mathrm{T}$ and $57 \mu \mathrm{T}$. Comparisons with reference paleointensity curves compiled from subaerial flows, archeomagnetic data and sedimentary records projected to the sampling site coordinates show that the measured values can be used to constrain the volcanic history of the ridge segments over the past few thousand years. A good agreement was found between apparent "freshness" of the glasses, the geochemistry of the lavas, and their magnetic paleointensity values. The inflated southern segment seems characterized by recent activities as indicated by numerous flows with paleointensities clustering around today's value $(39 \mu \mathrm{T})$ or around the high values typical of 2000-3000 years ago $(\sim 55 \mu \mathrm{T})$. We interpret this distribution to indicate the flooding by effusive lava flows of the entire axial plateau some 2000-3000 years ago, followed by a volcanic phase producing smaller volume lava flows confined to the innermost $200 \mathrm{~m}$ of the ridge axis. The northern ridge segment is characterized by dispersed paleointensity values consistent with a series of small eruptions of diverse ages. Samples collected at the tips of both ridge segments across the $16^{\circ} 20^{\prime} \mathrm{N}$ axial discontinuity have the lowest paleointensities and are thus thought to be significantly older, consistent with models advocating reduced magmatism near ridge axis discontinuities. This study demonstrates the strong potential of paleointensity measurements as a tool to help constrain volcanic history at ridge

axes. INDEX TERMS: 1521 Geomagnetism and Paleomagnetism: Paleointensity; 3035 Marine Geology and Geophysics: Midocean ridge processes; 8499 Volcanology: General or miscellaneous; KEYWORDS:

paleointensity, EPR, ridge

Citation: Carlut, J., M.-H. Cormier, D. V. Kent, K. E. Donnelly, and C. H. Langmuir (2004), Timing of volcanism along the northern East Pacific Rise based on paleointensity experiments on basaltic glasses, J. Geophys. Res., 109, B04104, doi:10.1029/2003JB002672.

\footnotetext{
${ }^{1}$ Also at Lamont-Doherty Earth Observatory, Columbia University, Palisades, New York, USA.

${ }^{2}$ Also at Department of Geological Sciences, Rutgers, The State University, New Brunswick, New Jersey, USA.

${ }^{3}$ Now at Department of Earth and Planetary Sciences, Harvard University, Cambridge, Massachusetts, USA.

Copyright 2004 by the American Geophysical Union. 0148-0227/04/2003JB002672\$09.00
}

\section{Introduction}

[2] Mid-ocean ridges are the most active volcanic features on the planet [Crisp, 1984]. Simple calculations that take into account spreading rates and the presumed thickness of feeder dikes provide first-order estimates on eruption frequencies. Sheeted dike complexes exposed in ophiolites and along escarpments near the East Pacific Rise 
(EPR) indicate that individual dikes are about $1 \mathrm{~m}$ thick [e.g., MacLeod and Rothery, 1992; Karson et al., 1992]. Spreading rates along the EPR range from 80 to $150 \mathrm{~mm} / \mathrm{yr}$, implying that a single dike may be injected every 713 years. Alternatively, dike swarms may be injected during volcanic episodes every century or more. In addition, while seafloor spreading may be uniform along the ridge, visual observations of the sea floor often show that flows appear to be older at segment ends compared to segment centers [e.g., Macdonald et al., 1988]. Therefore the entire volcanological behavior of the ocean ridge system remains to be confirmed.

[3] In addition, the age distribution of lavas both alongstrike and across-strike remains an open question: Do young flows extend several kilometers across the axis, putting "zero age" lava on top of crust that is many tens of thousands of years old? Is there a regular age distribution along-strike from segment center to segment ends? Do offaxis eruptions occur, or does all volcanic activity originate at the central point of dike injection?

[4] Answering such questions requires detailed knowledge of the age of volcanic eruptions along with the spatial distribution of the associated lavas. One approach would be to obtain direct evidence of the episodicity and extent of eruptions, but most ridges are far from land, and only short sections of ridge have so far been able to be monitored. Some baselines for long-term monitoring of volcanic activity along the EPR were established within the past decade with some detailed near-bottom surveys near $9^{\circ} 50^{\prime} \mathrm{N}$ and $17^{\circ} 25^{\prime} \mathrm{S}$. Eruptions took place in 1989 at $9^{\circ} 50^{\prime} \mathrm{N}$ [Haymon et al., 1993] and in the late 1980 's-early 1990 's at $17^{\circ} 25^{\prime} \mathrm{S}$ [Auzende et al., 1996; Embley et al., 1998; Sinton et al., 2002]. Eruptive activity has not yet recurred in either area and therefore the lateral extent and repeat rate of eruptions are simply unknown.

[5] Dating of young lavas is obviously critical to an understanding of eruptive activity at mid-ocean ridges but it remains problematic [see Christie, 1994]. Several isotopic methods have tentatively been applied, in particular $\mathrm{Po}-\mathrm{Pb}$ radioactive disequilibrium [Rubin et al., 1994, 1998] and other U-series dating techniques [Goldstein et al., 1991, 1994], but these are not completely adequate for estimating eruptive episodicity. Eruptive activity probably falls somewhere beyond the applicable age range of $\mathrm{Po}-\mathrm{Pb}$ and Th-Ra-U.

[6] The ages of exposed lavas in the axial region have been estimated on the basis of sediment cover and on the degree of tectonization and alteration [Macdonald et al., 1988]; recent age evaluation techniques may also involve the presence and maturity of hydrothermal sites and their biological communities, although it might provide inconsistent results in some cases [e.g., Milligan and Tunnicliffe, 1994]. These techniques are qualitative and dependent on our very partial understanding of interactions between volcanological, tectonic, hydrothermal and biological processes at the ridge axis. For example, sedimentation rates are strongly influenced by hydrothermal and tectonic activities and estimates may vary by an order of magnitude over distances of several kilometers [e.g., Marchig et al., 1986; Dekov and Kuptsov, 1992]. A quantitative method that could date MORB samples from the neovolcanic zone and differentiate products from successive volcanic eruptions on the expected recurrence timescales of around 50 to
100 years would bring about a breakthrough in our understanding of crustal accretion processes.

[7] Measurements of the Earth's magnetic field fossilized in rocks are an alternative approach that we investigate in the present study. Samples of baked earth have long been used to date archeological artifacts on land [see, e.g., Sternberg and McGuire, 1990; Le Goff et al., 2002]. Recent submarine basaltic glass (SBG) constitutes in theory and practice an ideal material for paleointensity investigations. The magnetic remanence carriers are small titano-magnetite grains in the super-paramagnetic (SP) to single domain (SD) range [Pick and Tauxe, 1994], and thus within the size range that should be subject to Néel theory for thermoremanence acquisition. Such a condition is a prerequisite for reliable Thellier paleointensity results. Furthermore, the magnetic grains within the glassy matrix do not seem to be sensitive to alteration at least on a $10^{6}$ yr timescale [Zhou et al., 1999]. Reliability of this material has been further tested in several studies showing that paleointensity results obtained from newly erupted flows give very accurate values when local magnetic anomalies are reasonably low [Pick and Tauxe, 1993; Kent and Gee, 1996; Carlut and Kent, 2000]. Although some questions remain on the exact nature of the remanence [see, e.g., Heller et al., 2002], the striking consistency between values for samples from the same flow and the very coherent results obtained on zero-age samples suggest that SBG can provide accurate values of paleointensity. Using several SBG samples from different locations within the same flow, Carlut and Kent [2000] obtained resolution of a paleointensity determination on the order of $1 \mu \mathrm{T}$. The high resolution of paleointensity measurements attainable on glasses led Carlut and Kent [2000] and Gee et al. [2000] to propose the use of paleointensity to infer an age on very young oceanic flow by reference to calibrated reference curves. The present study examines the feasibility of applying magnetic paleointensity measurements to determine the ages of distinct lava flows erupted in the axial region of the EPR.

\section{Geological Setting}

[8] The EPR between the Orozco and Rivera transform faults has been the subject of extensive studies [Macdonald et al., 1992; Weiland and Macdonald, 1996; Langmuir et al., 1998; Carbotte et al., 2000; Baker et al., 2001; Donnelly, 2002] (Figure 1). A 15-km-wide overlapping spreading center (OSC) partitions this first-order ridge segment near $16^{\circ} 20^{\prime} \mathrm{N}$ [Macdonald et al., 1992]. Both second-order segments have a similar intermediate spreading rate of $80-87 \mathrm{~mm} / \mathrm{yr}$ [Demets et al., 1994] but very contrasting characteristics. We refer hereafter to these two segments as $\mathrm{RO} 2$ and $\mathrm{RO} 3$ according to the nomenclature of Donnelly [2002]. Segment RO2, which extends north from the $16^{\circ} 20^{\prime} \mathrm{N}$ OSC to the Rivera transform fault near $18^{\circ} \mathrm{N}$, displays a morphology typical of intermediate spreading ridges, with a small rifted axial crest. In contrast, segment RO3, delimited by the Orozco transform fault and the $16^{\circ} 20^{\prime} \mathrm{N}$ OSC, is the shallowest and broadest along the entire EPR from $23^{\circ} \mathrm{S}$ to $23^{\circ} \mathrm{N}$ [Macdonald et al., 1992]. Its axial crest is exceptionally flat for most of its length, swelling from an average width of $3-4 \mathrm{~km}$ to about $10 \mathrm{~km}$ at $15^{\circ} 40^{\prime}-45^{\prime} \mathrm{N}$ (Figure 1). This inflated morphology 


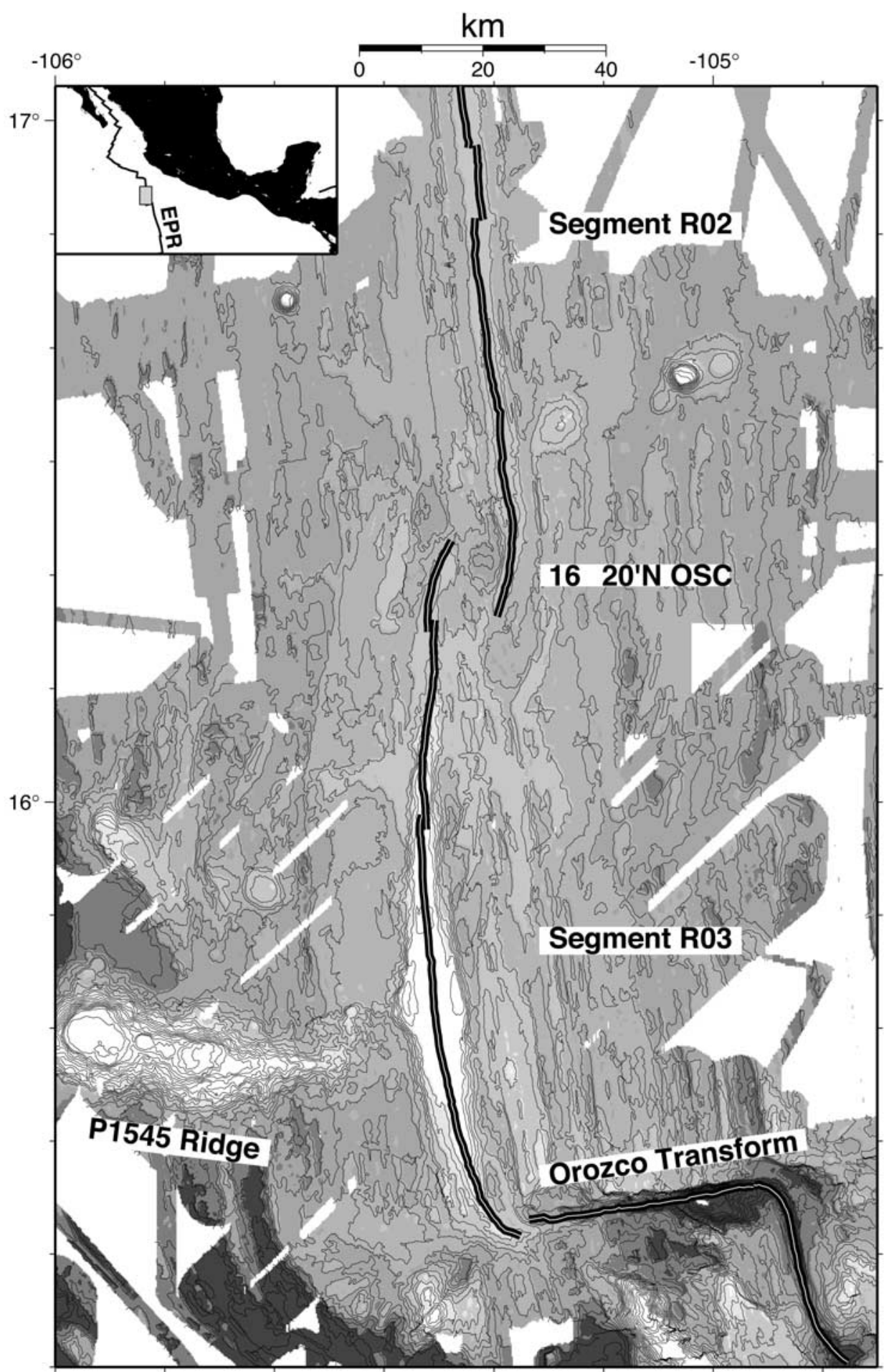

Figure 1. Main physiographic features of the study area. Bathymetry is compiled from data published by Macdonald et al. [1992], other publicly available multibeam data and data collected during expedition PANR01MV. Contour interval is $100 \mathrm{~m}$. Double line indicates the location of the EPR.

alone suggests a very robust magma supply [Scheirer and Macdonald, 1993]. Gravity analysis supports the presence of an unusually thick crustal section and/or the presence of a hotter mantle beneath the broad mid-segment section [Weiland and Macdonald, 1996]. A prominent volcanic ridge (the "P1545 ridge"), oriented parallel to Pacific absolute plate motion and as shallow as $1300 \mathrm{~m}$, approaches the ridge axis from the west near its broadest region [Macdonald et al., 1992; Weiland and Macdonald, 1996]. Tapping of the melt source associated with this "minihotspot" may be responsible for the magmatic robustness of the nearby ridge segment. 
[9] The $15^{\circ}-18^{\circ} \mathrm{N}$ area was the focus of a detailed geochemical sampling program during the 1997 expedition PANR01MV [Langmuir et al., 1998; Donnelly, 2002]. Both the ridge axis and the off-axis seamounts were systematically sampled in order to characterize the spatial and temporal geochemical dispersion of lavas. Dredges and rock cores were carefully sited by taking advantage of real-time multibeam bathymetry data and accurate positioning of the ship (both P-code GPS and dynamic positioning were available). We evaluate the maximum position uncertainty to be on the order of 100 meters. The thorough geochemical analyses provide a context for the evaluation of the paleointensity values with respect to morphological and petrological characteristics.

\section{Sampling and Experimental Procedure}

[10] Samples were all selected from the PANR01MV collection, with priority given to samples closest to the spreading axis. A crustal magnetization map for the area [Weiland and Macdonald, 1996, Figure 7] shows the presence of an area of high crustal magnetization at the southern part of the $16^{\circ} \mathrm{N}$ segment near the Orozco transform fault, consistent with the common occurrence of highmagnetization zones near some of the large ridge axis discontinuities along the EPR [Sempéré, 1991; Gee and Kent, 1998]. Accordingly, samples collected in that area are high Fe-Ti basalts [Donnelly, 2002]. Because strong local crustal magnetic fields could add a significant contribution to the geomagnetic field leading to variable values of the intensity on the scale of a flow [see, e.g., Carlut and Kent, 2000], samples south of $15^{\circ} 30^{\prime} \mathrm{N}$ were excluded from our selection.

[11] A total of 108 subsamples belonging to 36 different units (a dredge or a rock core) were selected for paleointensity measurements. As by Carlut and Kent [2000], samples were selected with initial magnetic moments greater than $5 \times 10^{-10} \mathrm{Am}^{2}$ since experimental noise levels were estimated to be about $1 \times 10^{-11} \mathrm{Am}^{2}$ or less. Most of the selected samples are SBG. While results obtained on glasses are thought to be very reliable [Pick and Tauxe, 1993; Mejia et al., 1996; Gee et al., 2000; Carlut and Kent, 2000] (however, see Heller et al. [2002] and Smirnov and Tarduno [2003]), results obtained from within the crystalline part of the samples can show apparent paleointensity values that can be considerably (up to 50\%) higher than expected [Carlut and Kent, 2002; see also Tauxe and Love, 2003]. This difference was attributed by Carlut and Kent [2002] to bias resulting from a multidomain contribution in the crystalline part of the samples. Concern was also expressed by Carlut and Kent [2002] about the tendency for a slight decrease in paleointensity values between results from glasses and from the first nonglassy subsample adjacent to the glassy margin. If verified, this could indicate that paleointensity from glasses is systematically high. To test this observation, we selected both the glasses and first cryptocrystalline sample (named with an added "a" to the sample name from Carlut and Kent [2002]; see also Carlut and Kent [2002, Figure 1]) lying within $5 \mathrm{~mm}$ from the glassy rime on a set of five lobate flows from the axial area in the $16^{\circ} \mathrm{N}$ area.
[12] We used the "Kasil-slide" procedure described in Carlut and Kent [2000] to mount the samples on microscope glass slides. The modified Thellier and Thellier method was used with pTRM-checks to test for possible alteration during the experiments [Coe, 1967]. Standard criteria of acceptance were used: a result is acceptable if there is a nearly constant ratio between lost and acquired magnetization over a wide range of natural remanent magnetization (NRM), demagnetization with partial thermoremanent magnetization (pTRM) checks within less than $5 \%$ of the initial pTRM values. All experiments were performed in air in a laboratory field of $35 \mu \mathrm{T}$.

[13] After the first heating step $\left(110^{\circ} \mathrm{C}\right)$ almost all samples show a single demagnetization component on the directional diagram and were almost totally demagnetized between $400^{\circ} \mathrm{C}$ and $560^{\circ} \mathrm{C}$ for the glasses and $350^{\circ}$ and $500^{\circ} \mathrm{C}$ for the basalt margin samples. An examination of the total moment left after each heating step reveals the coexistence of two distinct populations in some glassy samples (see Figure 2a), characterized by a dominant fraction with demagnetization temperatures below $450^{\circ}$ and a smaller fraction with demagnetization temperature between 540 and $560^{\circ} \mathrm{C}$, probably reflecting the coexistence of two populations with different ulvospinel contents.

[14] Results of the Thellier experiments are presented in Arai plots (Figure 2). Among the initial 108 samples, 63 gave acceptable results ( $58 \%$ success rate); the others were rejected mostly because of negative pTRM-checks. The weakest samples in terms of NRM are often associated with bad experimental behavior during the paleointensity experiment. If we only select samples with NRM above $2 \times 10^{-9} \mathrm{Am}^{2}, 93$ samples remain from the initial 108 samples selected but 62 within this new collection are successful $(67 \%$ success rate). This suggests that sample selection should be based on a higher initial magnetization threshold than imposed by experimental noise level.

[15] On average, the successful samples have a high quality factor (q) ranging from 5 to 94 , with a mean value of 34 . Paleointensity values range from $7.8 \mu \mathrm{T}$ to $59.6 \mu \mathrm{T}$. For all units, the dispersion around the mean paleointensity value is very low (less than 10\%) as previously observed in this material by several authors [e.g., Mejia et al., 1996; Pick and Tauxe, 1993; Carlut and Kent, 2000]. A total of 27 units (independent dredges or rock core) gave acceptable results, which are listed in Table 1.

\section{Results}

\subsection{Cryptocrystalline Versus Glassy Samples}

[16] To address the question of the systematic differences between the values obtained on glasses and on the first adjacent, cryptocrystalline (nonglassy) sample, we combined our results with those obtained previously by Kent and Gee [1996], Carlut and Kent [2000], and Carlut and Kent [2002]. All results are summarized in Table 2. The data come from three lobate samples from the southern EPR, two pillow samples from the Juan de Fuca Ridge, and five lobate samples from the present study. In Figure 3, the mean paleointensity value from each different pillow or lobate glass sample is compared with the value obtained for the more slowly cooled first cryptocrystalline subsample. Given the uncertainties in paleointensity estimates, the mean 
a)

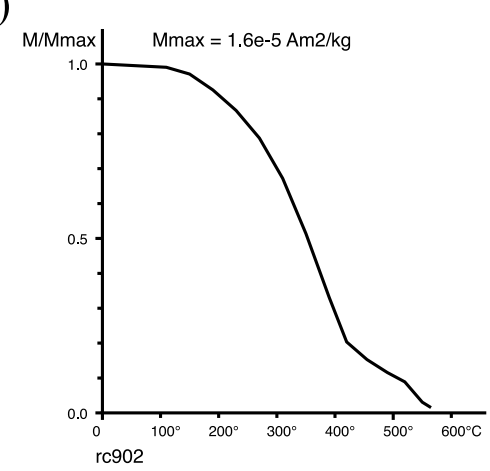

b)

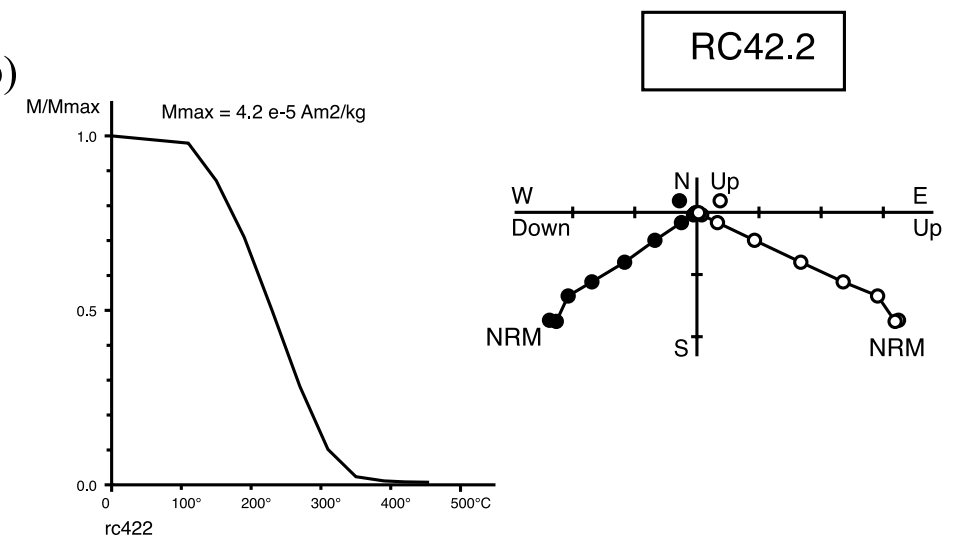

c)

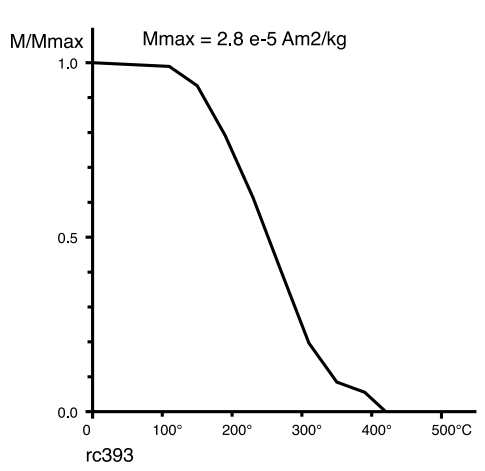

d)

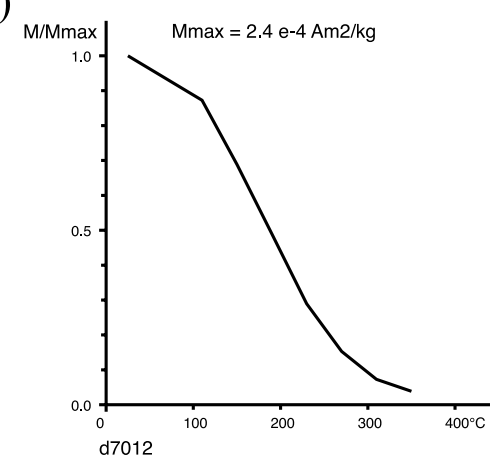

RC90.2
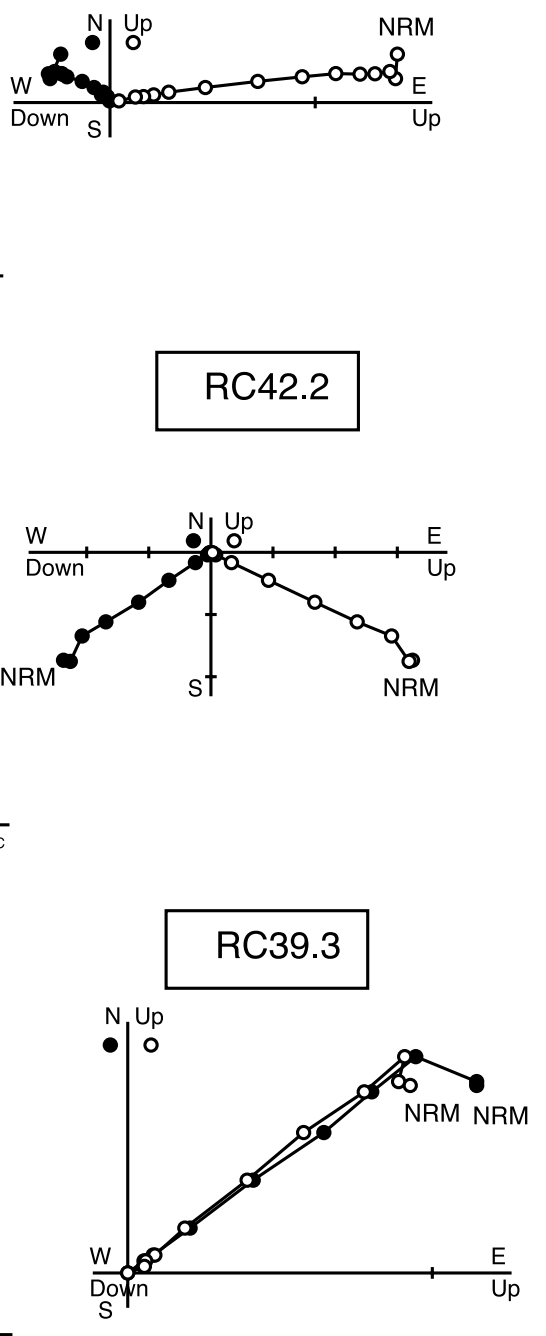

D70-1.2

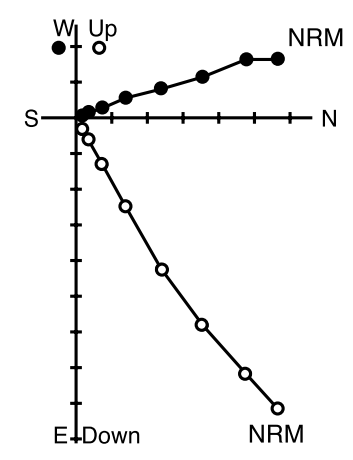

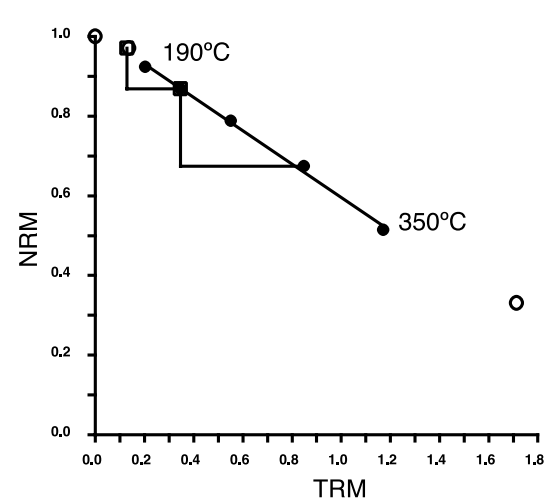
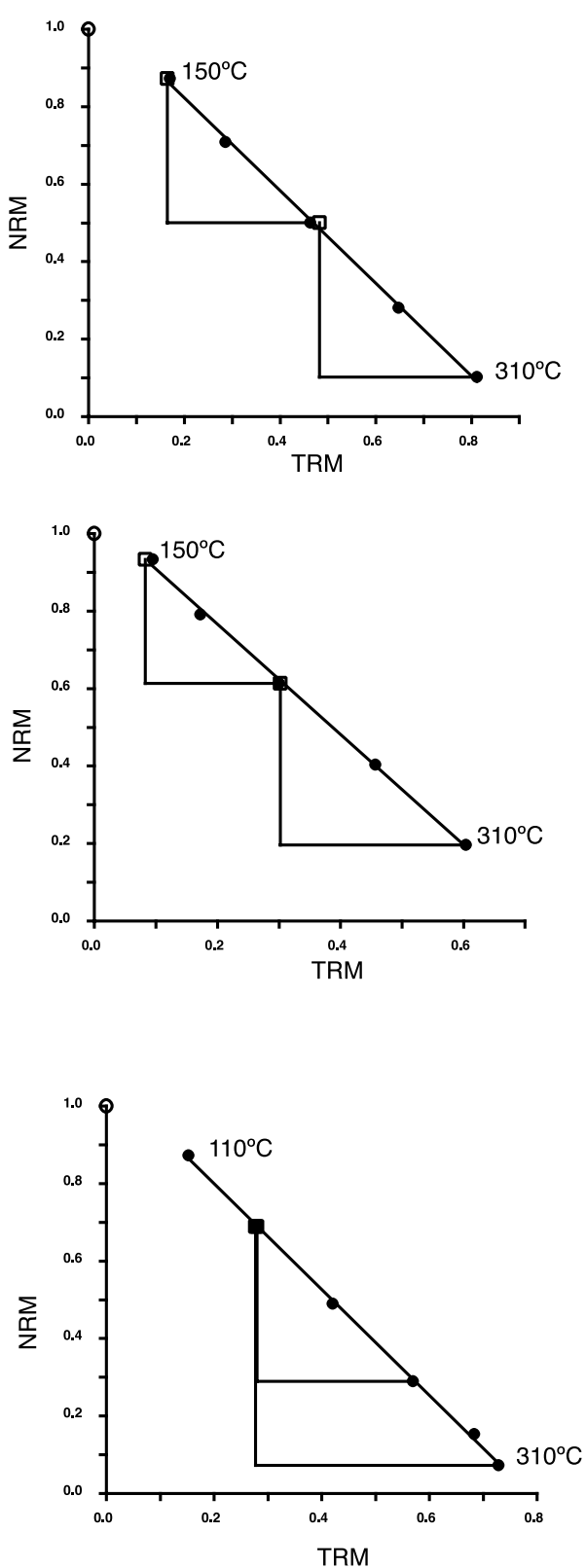

Figure 2. Magnetic moments, Zijderveld diagrams and NRM versus TRM (Arai) diagrams for four typical samples. Temperature steps are $20^{\circ} \mathrm{C}, 150^{\circ} \mathrm{C}$ then every $40^{\circ} \mathrm{C}$ until $550^{\circ} \mathrm{C}$ or less depending on the remanent magnetization left in the sample. 
Table 1. Results of Absolute Paleointensity Experiments ${ }^{\mathrm{a}}$

\begin{tabular}{|c|c|c|c|c|c|c|c|c|c|c|}
\hline$\underline{\text { Latitude }}$ & Subsample & $\mathrm{NRM} 10^{-3} \mathrm{Am}^{2} / \mathrm{kg}$ & Delta $\mathrm{T},{ }^{\circ} \mathrm{C}$ & $\mathrm{f}$ & $\mathrm{g}$ & $\mathrm{q}$ & $\mathrm{Fa}, \mu \mathrm{T}$ & $\sigma / \mathrm{b}$ & $\mathrm{F}_{\text {tot }}, \mu \mathrm{T}$ & $2 \sigma \mathrm{SE}, \mu \mathrm{T}$ \\
\hline 15.69 & RC53.2 & 0.246 & $150-270$ & 0.42 & 0.65 & 10.2 & 52.1 & 0.03 & 52.1 & 2.8 \\
\hline 15.71 & D22-7.a1 & 0.041 & $30-270$ & 0.89 & 0.59 & 16.4 & 38.1 & 0.03 & & \\
\hline 15.71 & D22-7.a2 & 0.028 & $110-270$ & 0.34 & 0.65 & 9.9 & 44.1 & 0.02 & 41.1 & 6.0 \\
\hline 15.72 & D21-3.3 & 0.205 & $150-310$ & 0.65 & 0.75 & 41.9 & 53.7 & 0.01 & & \\
\hline 15.72 & D21-3.2 & 0.167 & $110-310$ & 0.76 & 0.8 & 29.5 & 56.3 & 0.02 & & \\
\hline 15.72 & D21-3.1 & 0.062 & $25-310$ & 0.85 & 0.82 & 59.3 & 52.6 & 0.01 & & \\
\hline 15.72 & D21-3.a1 & 1.155 & $110-270$ & 0.56 & 0.71 & 29.1 & 57.2 & 0.01 & & \\
\hline 15.72 & D21-3.a2 & 0.309 & $150-270$ & 0.43 & 0.66 & 26 & 52 & 0.01 & 54.4 & 2.0 \\
\hline 15.73 & RC82.3 & 0.151 & $150-270$ & 0.44 & 0.67 & 5 & 50.8 & 0.06 & & \\
\hline 15.73 & RC82.1 & 0.009 & $150-350$ & 0.74 & 0.78 & 39.1 & 58.1 & 0.01 & 54.4 & 7.3 \\
\hline 15.82 & D63.a1 & 4.164 & $110-270$ & 0.64 & 0.74 & 21.5 & 54 & 0.02 & 54 & 2.3 \\
\hline 15.85 & D20-1.2 & 0.01 & $110-310$ & 0.5 & 0.79 & 15.7 & 38.5 & 0.03 & 38.5 & 1.9 \\
\hline 15.85 & D20-7.a1 & 0.247 & $110-270$ & 0.65 & 0.66 & 39.6 & 40.4 & 0.01 & 40.4 & 0.9 \\
\hline 15.90 & RC90.2 & 0.016 & $190-350$ & 0.4 & 0.72 & 8.6 & 14.7 & 0.03 & & \\
\hline 15.90 & RC90.1 & 0.008 & $150-350$ & 0.38 & 0.76 & 26.2 & 16.9 & 0.01 & 15.8 & 2.2 \\
\hline 15.93 & $\mathrm{RC} 42.3$ & 0.016 & $190-310$ & 0.62 & 0.66 & 33.9 & 37 & 0.01 & & \\
\hline 15.93 & $\mathrm{RC} 42.2$ & 0.042 & $150-310$ & 0.72 & 0.75 & 25.7 & 41.9 & 0.02 & & \\
\hline 15.93 & RC42.1 & 0.36 & $110-310$ & 0.82 & 0.79 & 89.1 & 41.2 & 0.01 & 40.0 & 3.1 \\
\hline 15.97 & RC39.3 & 0.028 & $150-310$ & 0.69 & 0.74 & 20.1 & 49.9 & 0.03 & & \\
\hline 15.97 & RC39.2 & 0.011 & $150-310$ & 0.64 & 0.74 & 40.8 & 49.1 & 0.01 & 49.5 & 0.8 \\
\hline 15.99 & RC38.3 & 0.021 & $150-350$ & 0.7 & 0.79 & 35.4 & 49.9 & 0.02 & 49.9 & 1.6 \\
\hline 16.02 & RC96.a1 & 0.675 & $150-350$ & 0.66 & 0.79 & 23.2 & 43.3 & 0.02 & & \\
\hline 16.02 & RC96.a2 & 2.079 & $150-350$ & 0.68 & 0.77 & 25.4 & 53 & 0.02 & 48.1 & 9.7 \\
\hline 16.02 & D71-2.1 & 0.255 & $230-350$ & 0.48 & 0.65 & 12.4 & 42.7 & 0.03 & & \\
\hline 16.02 & D71-2.2 & 0.08 & $150-350$ & 0.67 & 0.79 & 16.5 & 47.7 & 0.03 & & \\
\hline 16.02 & D71-2.3 & 0.15 & $150-350$ & 0.69 & 0.73 & 23.6 & 47.5 & 0.02 & & \\
\hline 16.02 & D71-2.a1 & 3.259 & $150-310$ & 0.72 & 0.74 & 76.4 & 49.3 & 0.01 & & \\
\hline 16.02 & D71-2.a2 & 0.913 & $30-350$ & 0.88 & 0.82 & 55.3 & 50.6 & 0.01 & 47.6 & 2.7 \\
\hline 16.02 & D71-1.1 & 0.075 & $150-350$ & 0.7 & 0.77 & 44.7 & 53.3 & 0.01 & & \\
\hline 16.02 & D71-1.2 & 0.035 & $150-350$ & 0.55 & 0.77 & 10.8 & 59.2 & 0.07 & & \\
\hline 16.02 & D71-1.3 & 0.095 & $150-350$ & 0.75 & 0.75 & 85.2 & 55 & 0.01 & & \\
\hline 16.02 & D71-1.a1 & 18.498 & $110-270$ & 0.69 & 0.73 & 80.9 & 57.7 & 0.01 & & \\
\hline 16.02 & D71-1.a2 & 13.814 & $150-310$ & 0.72 & 0.74 & 47.8 & 59.6 & 0.01 & 57.0 & 2.4 \\
\hline 16.02 & D70-1.2 & 0.239 & $110-310$ & 0.74 & 0.78 & 41 & 47.8 & 0.01 & & \\
\hline 16.02 & D70-1.a & 0.053 & $110-270$ & 0.45 & 0.75 & 21.8 & 43.4 & 0.02 & 45.6 & 4.4 \\
\hline 16.02 & D72-5.1 & 0.002 & $190-350$ & 0.39 & 0.74 & 5.3 & 20.5 & 0.05 & & \\
\hline 16.02 & D72-5.3 & 0.003 & $190-310$ & 0.28 & 0.64 & 54.1 & 21.1 & 0 & & \\
\hline 16.02 & D72-5.2 & 0.014 & $150-270$ & 0.33 & 0.65 & 36.8 & 18.4 & 0.01 & 20.0 & 1.6 \\
\hline 16.02 & D72-2.1 & 0.004 & $190-350$ & 0.4 & 0.74 & 8 & 19.3 & 0.04 & 19.3 & 1.4 \\
\hline 16.02 & D72-3.1 & 0.178 & $150-270$ & 0.45 & 0.67 & 7.5 & 16.3 & 0.04 & & \\
\hline 16.02 & D72-3.2 & 0.138 & $150-270$ & 0.46 & 0.67 & 9.8 & 16 & 0.03 & 16.1 & 0.3 \\
\hline 16.21 & $\mathrm{RC} 33.2$ & 0.014 & $190-350$ & 0.55 & 0.73 & 10.9 & 58 & 0.04 & & \\
\hline 16.21 & $\mathrm{RC} 33.1$ & 0.03 & $150-350$ & 0.67 & 0.79 & 27.7 & 49 & 0.02 & 53.5 & 9.0 \\
\hline 16.25 & RC32.1 & 0.037 & $110-350$ & 0.7 & 0.82 & 24 & 8.2 & 0.02 & & \\
\hline 16.25 & $\mathrm{RC} 32.2$ & 0.039 & $110-310$ & 0.57 & 0.79 & 28.5 & 7.8 & 0.02 & 8.0 & 0.4 \\
\hline 16.28 & D18-1.2 & 0.41 & $30-270$ & 0.81 & 0.79 & 32.8 & 26.1 & 0.02 & & \\
\hline 16.28 & D18-1.1 & 0.185 & $110-270$ & 0.64 & 0.74 & 24.9 & 24.7 & 0.02 & & \\
\hline 16.28 & D18-1.a1 & 0.979 & $30-270$ & 0.82 & 0.79 & 39.5 & 25.6 & 0.02 & & \\
\hline 16.28 & D18-1.a2 & 1.541 & $30-270$ & 0.82 & 0.79 & 46.7 & 26.7 & 0.01 & 25.8 & 0.9 \\
\hline 16.42 & $\mathrm{RC} 28.3$ & 0.106 & $110-270$ & 0.48 & 0.75 & 12.5 & 46 & 0.03 & & \\
\hline 16.42 & $\mathrm{RC} 28.1$ & 0.048 & $110-310$ & 0.61 & 0.79 & 25.4 & 51 & 0.02 & 48.5 & 5.0 \\
\hline 16.55 & RC26.2 & 0.007 & $150-350$ & 0.73 & 0.76 & 29.1 & 39.1 & 0.02 & & \\
\hline 16.55 & $\mathrm{RC} 26.1$ & 0.007 & $150-310$ & 0.53 & 0.72 & 7.7 & 42.3 & 0.05 & 40.7 & 3.2 \\
\hline 16.73 & $\mathrm{RC} 23.2$ & 0.012 & $110-310$ & 0.74 & 0.79 & 29.1 & 50.5 & 0.02 & 50.5 & 2.0 \\
\hline 16.80 & D9-8.3 & 0.22 & $110-350$ & 0.84 & 0.82 & 91.3 & 57.3 & 0.01 & & \\
\hline 16.80 & D9-8.2 & 0.174 & $110-310$ & 0.72 & 0.79 & 67 & 53.2 & 0.01 & & \\
\hline 16.80 & D9-8.1 & 0.1 & $110-310$ & 0.69 & 0.78 & 51 & 55 & 0.01 & & \\
\hline 16.80 & D9-8.a1 & 0.371 & $150-310$ & 0.62 & 0.75 & 32.4 & 56 & 0.01 & & \\
\hline 16.80 & D9-8.a2 & 0.404 & $110-310$ & 0.77 & 0.8 & 94.2 & 53.9 & 0.01 & 55.1 & 1.5 \\
\hline 16.99 & $\mathrm{RC} 21.2$ & 0.156 & $190-350$ & 0.69 & 0.74 & 31.4 & 45.2 & 0.02 & & \\
\hline 16.99 & $\mathrm{RC} 21.1$ & 0.009 & $110-350$ & 0.73 & 0.82 & 60.9 & 46.6 & 0.01 & 45.9 & 1.4 \\
\hline 17.07 & RC109.2 & 0.003 & $150-270$ & 0.39 & 0.66 & 9.3 & 48.7 & 0.03 & & \\
\hline 17.07 & RC109.1 & 0.013 & $150-310$ & 0.5 & 0.74 & 60.4 & 51.2 & 0.01 & 50.0 & 2.5 \\
\hline
\end{tabular}

"Site latitude is in decimal degree. Subsample names are as follows: "RC" indicates a rock core, "D" indicates a dredge, and the letter "a" after the dot indicates a cryptocrystalline sample. NRM, natural remanent magnetization; delta $\mathrm{T}$ is temperature range; $\mathrm{f}$ is fraction factor, $\mathrm{g}$ is gap factor, $\mathrm{q}$ is quality factor (see Coe et al. [1978] for a description of the $\mathrm{f}, \mathrm{g}$ and $\mathrm{q}$ factors); $\mathrm{F}_{\mathrm{a}}$ and $\sigma / \mathrm{b}$ are paleointensity and standard error normalized by the paleointensity for individual specimens; $\mathrm{F}_{\text {tot }}$ and $2 \sigma$ are unweighted mean paleointensity and corresponding $95 \%$ standard error (in $\mu \mathrm{T}$ ) for individual units. 
Table 2. Comparison Between Paleointensity Results Obtained on Glasses and on the First Cryptocrystalline Samples ${ }^{\mathrm{a}}$

\begin{tabular}{|c|c|c|c|c|c|c|c|c|c|}
\hline Sample & Published & Location & $\begin{array}{c}\text { Number of } \\
\text { Glassy } \\
\text { Subsamples } \\
\text { Used }\end{array}$ & $\begin{array}{c}\mathrm{F}_{\text {tot }} \text { Glass } \\
\text { Subsamples, } \\
\mu \mathrm{T}\end{array}$ & $\begin{array}{c}\mathrm{F}_{\text {tot }} \text { Glass } \\
2 \sigma \mathrm{SE}(95 \%), \\
\mu \mathrm{T}\end{array}$ & $\begin{array}{c}\text { Number of } \\
\text { “a” Subsamples } \\
\text { Used }\end{array}$ & $\begin{array}{c}\text { F tot } \text { "a" } \\
\text { Subsamples, } \\
\mu \mathrm{T}\end{array}$ & $\begin{array}{c}\mathrm{F}_{\text {tot }} \text { "a" } \\
2 \sigma \mathrm{SE} \\
(95 \%), \\
\mu \mathrm{T}\end{array}$ & Delta, $\mu \mathrm{T}$ \\
\hline $\mathrm{R} 2-93$ & $\begin{array}{l}\text { Carlut and } \\
\text { Kent [2002] }\end{array}$ & $\mathrm{JdF} 46^{\circ} \mathrm{N}$ & 12 & 73.6 & 3.8 & 1 & 60.2 & 1.0 & 13.4 \\
\hline R1-93 & $\begin{array}{l}\text { Kent and Gee [1996]; } \\
\quad \text { Carlut and Kent [2000] }\end{array}$ & $\mathrm{JdF} 46^{\circ} \mathrm{N}$ & 7 & 53.3 & 3.2 & 1 & 52.8 & 0.2 & 0.5 \\
\hline $3349-2$ & Carlut and Kent [2002] & EPR $18^{\circ} \mathrm{S}$ & 5 & 34.5 & 1.4 & 1 & 31.0 & 1.2 & 3.5 \\
\hline $3346-15$ & Carlut and Kent [2002] & EPR $18^{\circ} \mathrm{S}$ & 3 & 36.6 & 2.4 & 1 & 33.3 & 0.6 & 3.3 \\
\hline $3344-6$ & Carlut and Kent [2002] & EPR $18^{\circ} \mathrm{S}$ & 3 & 36.5 & 1.6 & 1 & 33 & 1.0 & 3.5 \\
\hline D71-2 & this study & EPR $16^{\circ} \mathrm{N}$ & 3 & 45.9 & 3.2 & 2 & 49.9 & 1.3 & -4 \\
\hline D71-1 & this study & EPR $16^{\circ} \mathrm{N}$ & 3 & 55.8 & 3.4 & 2 & 58.6 & 1.9 & -2.8 \\
\hline D70-1 & this study & EPR $16^{\circ} \mathrm{N}$ & 1 & 47.8 & 0.3 & 1 & 43.4 & 0.3 & 4.4 \\
\hline D18-1 & this study & $\mathrm{EPR} 16^{\circ} \mathrm{N}$ & 2 & 25.4 & 1.4 & 2 & 26.1 & 1.1 & -0.7 \\
\hline D9-8 & this study & EPR $17^{\circ} \mathrm{N}$ & 3 & 55.2 & 2.4 & 2 & 54.9 & 2.1 & 0.3 \\
\hline
\end{tabular}

${ }^{a} \mathrm{JdF}$ refers to samples from the Juan de Fuca ridge, and EPR refers to samples from the East Pacific Rise; $\mathrm{F}_{\text {tot }}$ glass and $2 \sigma$ SE, unweighted mean paleointensity and $95 \%$ standard error (in $\mu \mathrm{T}$ ) from the glassy subsamples set or from individual specimens when only one specimen is available, $\mathrm{F}_{\text {tot }}$ " $\mathrm{a}$ " and $2 \sigma \mathrm{SE}$, unweighted mean paleointensity and 95\% standard error (in $\mu \mathrm{T}$ ) from the cryptocrystalline samples set or from individual specimens when only one specimen is available; Delta, difference between the mean paleointensity from glasses and the mean paleointensity from cryptocrystalline subsamples.

values obtained on glasses are in all but one case within $10 \%$ of the values obtained on the cryptocrystalline material and are dispersed around the ideal correlation line. No tendency for a systematic bias between glasses and the first cryptocrystalline samples is found. The only significant outlier is the R2-93 sample described by Carlut and Kent [2002]; the very high iron content $(\sim 13.0 \mathrm{wt} \% \mathrm{FeO} *$, M. Perfit, personal communication) and NRM intensity ( $\sim 100 \mathrm{Am}^{-1}$ [Tivey et al., 1998]) of this particular sample may indicate high concentration in magnetic grains leading to interactions between them and therefore a complex magnetic recording process.

[17] From this set of data we conclude that, in general, the best paleointensity estimate for such young flows is probably the mean value of the glasses and adjacent nonglassy sample. This strengthens confidence in paleointensity results obtained on the outermost part of the flows whether it is glassy or not as long as it contains mainly SP to SD populations (i.e., lies within a few millimeters of the glassy margin).

\subsection{The $16^{\circ} \mathrm{N}$ Collection}

[18] Mean paleointensity results obtained for each unit are presented on a histogram in Figure 4. A striking feature is the number of flows giving results well above today's geomagnetic field value: 16 units range from 44 to $57 \mu \mathrm{T}$, 5 units are very close to today's value (around $39 \mu \mathrm{T}$ ) and 6 units show low values (from 8 to $25 \mu \mathrm{T}$ ).

[19] It has been suggested that the remanence in SBG may be a grain growth chemical remanent magnetization (CRM) rather than a thermoremanent magnetization (TRM) [Heller et al., 2002], which would lead to lower estimates of paleointensity. This would not explain the high values found in this set of samples. Instead, the high intensity found in samples close to the ridge axis suggests a record of a stronger geomagnetic field in very recent times.

\section{Introduction of a Time Frame}

[20] Changes in intensity of the Earth's magnetic field during the last few thousand years are now documented but the data sets remain very heterogeneous. A critical part of the analysis of the paleointensity data is the compilation of an accurate data set in order to compare our results to an age-calibrated reference curve. The past $50 \mathrm{kyr}$ are the focus of this analysis as it corresponds to approximately $4 \mathrm{~km}$ across axis (assuming a full spreading rate of $\sim 80 \mathrm{~mm} / \mathrm{yr}$ ), which includes almost all samples studied here.

[21] Three different kinds of paleointensity data can be used for this period:

[22] 1. Geomagnetic intensity for the sampling site derived from the 400 years of historical models of the field based on the modern International or Definitive Geomagnetic Reference Fields (IGRF or DGRF) and the spherical harmonic model for historical time of Jackson et al. [2000], although prior to 1838 the lack of direct measurements of field intensity does not allow very trustworthy values.

[23] 2. Absolute paleointensity data for the past $50 \mathrm{kyr}$ based on the Thellier-Thellier method as first compiled by McElhinny and Senanayake [1982] and updated in the most recent part by Yang et al. [2000] (see also the global data set described by Perrin et al. [1998]). A concern with this data set is the heterogeneity in the experimental methodology, and therefore in the quality of results.

[24] 3. Relative sedimentary paleointensity records obtained from continuous sediment sections. A global set was compiled for the last $800 \mathrm{kyr}$ by Guyodo and Valet [1999] and reflects mainly the dipole field variations since higher frequency variations were smoothed by the recording process and/or by stacking.

[25] The ideal set to compare the SBG paleointensity data would integrate dipole and nondipole paleointensity variations at the $16^{\circ} \mathrm{N}$ site and be well constrained in time and homogeneous in term of sampling and quality. High quality absolute paleointensity data from locations close to the $16^{\circ} \mathrm{N}$ area and associated with precise dating are therefore the most relevant for our purposes. We have updated and critically evaluated the absolute paleointensity set of Perrin et al. [1998] for the past $50 \mathrm{kyr}$. Stringent selection criteria were applied in order to exclude data which could be erroneous or do not have the required age or paleointensity precision. To be eligible, data should be produced using the 


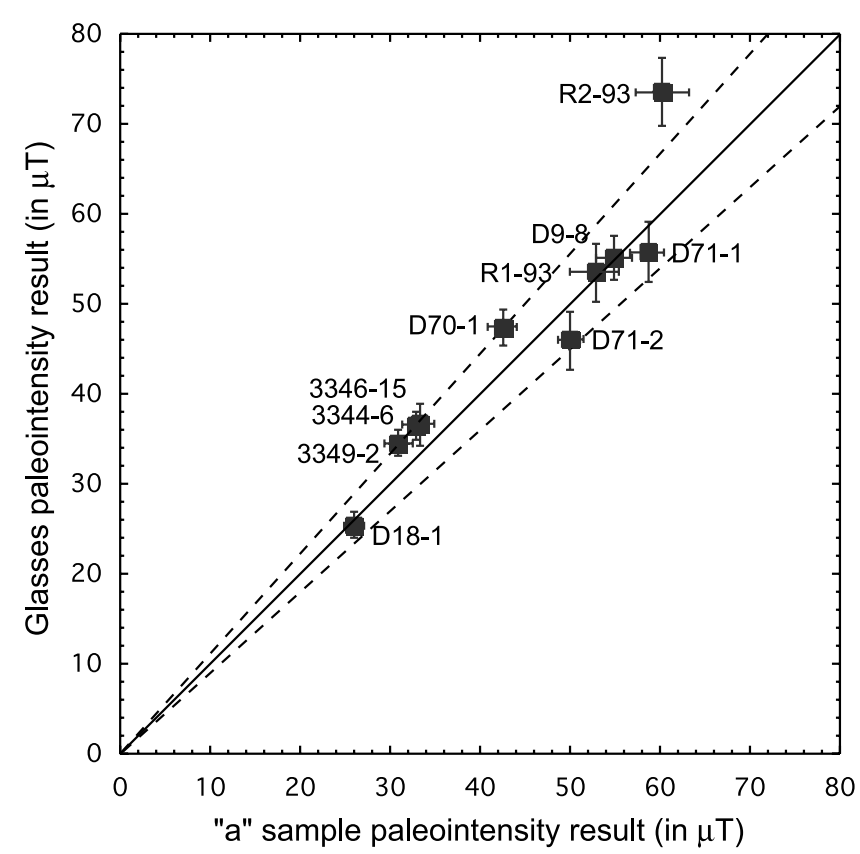

Figure 3. Mean paleointensity results obtained from submarine basaltic glasses (see also Table 2) as a function of the mean paleointensity results obtained from the adjacent first cryptocrystalline subsamples. Given the error bars, all data points except R2-93 are lying within $10 \%$ of the ideal correlation line, $10 \%$ limits around the ideal correlation line are represented as dotted lines.

Thellier and Thellier method with pTRM-checks, have a mean quality factor, $\mathrm{q}$, above 3 , and be associated with a precise ( \pm a few hundreds of years) radiometric or historical age. In order to compare data from different locations, paleointensity values should be normalized with respect to the site latitude by conversion to a Virtual Axial Dipole Moment (VADM). The VADM should therefore be explicitly given if no precise location is provided. As feared, given the selection criteria used, very few data in the vicinity of the $16^{\circ} \mathrm{N}$ area remains. We therefore selected an area within $60^{\circ}$ of latitude and $60^{\circ}$ of longitude of the EPR site as a compromise to preserve the possible record of local nondipole components, $60^{\circ}$ being roughly the spatial scale of major nondipole features using the current IGRF model (see, as an example, map of the nondipole field by McElhinny and McFadden [2000]), while trying to keep a reasonable number of data. Studies remaining in the restricted data set include results from Hawaii, the western United States, Ecuador and the EPR. The study by Yu et al. [2000] from Ontario potsherds from the last 2000 years was not included in the set because the authors stated that results are probably "affected by a substantial nondipole field" which, if confirmed, would characterize the northeastern part of North America and therefore not be representative of the field in the $16^{\circ} \mathrm{N}$ EPR region. A list of all studies considered is presented in Table 3 .

[26] The volcanic set contains a total of 78 data, ranging in age from 28140 B.P. to 2000 A.D. Data were transformed to VADM and transformed again in equivalent intensity for $16^{\circ} \mathrm{N}$ latitude. All results are plotted on Figure 5a. Despite the stringent selection criteria a large scatter remain in the data. An illustration is given by samples RD35-4 and RD37-2 (see Figure 5a) from the EPR reported by Pick and Tauxe [1993], which are supposed to be less than 100 years apart in age (respectively 1190 and 1280 years BP following ${ }^{226} \mathrm{Ra} /{ }^{230} \mathrm{Th}$ dating quoted by the authors as a personal communication from K. H. Rubin and J. D. MacDougall) but are reported in the original study to have mean intensities of $17.5 \mu \mathrm{T}$ and $42.4 \mu \mathrm{T}$ or equivalent VADM of $3.8 \times 10^{22} \mathrm{Am}^{2}$ and $9.4 \times 10^{22} \mathrm{Am}^{2}$, respectively. This huge difference in field intensity over such a very short time interval is hardly explicable in terms of geomagnetic field behavior. As a comparison, the VADM intensity of the field at the $16^{\circ} \mathrm{N}$ EPR site over the 100 year period from $1900 \mathrm{AD}$ and $2000 \mathrm{AD}$ changed only from approximately $9 \times 10^{22} \mathrm{Am}^{2}$ to $8 \times 10^{22} \mathrm{Am}^{2}$, even though we may be in a period of rapid variations perhaps due to the emergence of reverse polarity fluxes in the Earth's liquid core [see Hulot et al., 2002]. A large uncertainty in the quoted ages is one factor that could explain such a discrepancy between those two paleointensity values.

[27] A locally weighted polynomial regression method (LOESS method [see Cleveland, 1979]), which has a low sensitivity to outliers, was applied to the compilation with the idea of not "over fitting" the data while preserving most of the structures. We used local quadratic polynomial fits on small successive subsets $(15 \%)$ of data; a final smoothed curve is presented in Figure 5a and explains approximately $65 \%$ of the data. Better fits produce lots of wiggles in response to the high fluctuations of the data and were disregarded. Since this curve does not provide the required level of precision and there are presently no acceptable data older than approximately $28 \mathrm{ka}$, we also considered the worldwide absolute compilations of Yang et al. [2000] and the normalized sedimentary SINT800 record [Guyodo and Valet, 1999]. By nature, the data from these two compilations are smoothed and do not specifically reflect absolute intensity variations at a particular location, such as along the EPR, but we believe that these compilations give the best

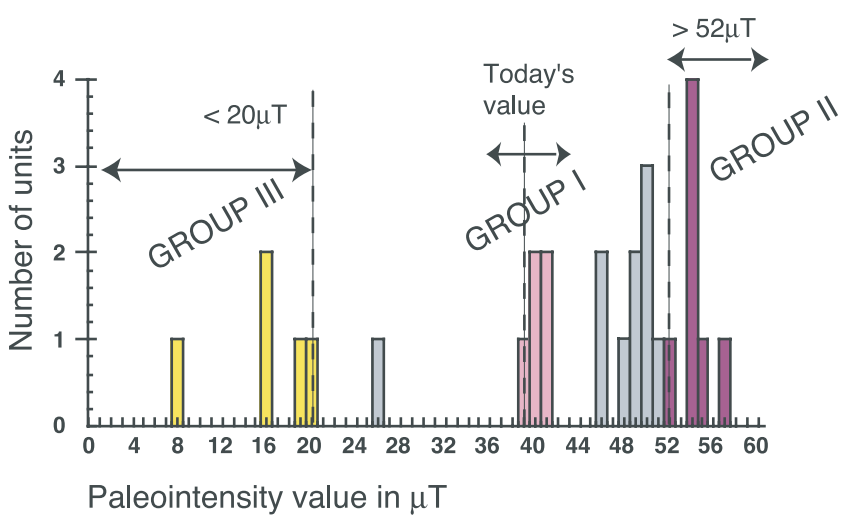

Figure 4. Histogram of the mean paleointensity results found along the R02 and R03 segments. Three groups of flow clustering close to today's value at the site $(39 \mu \mathrm{T}$, Group I), above $52 \mu \mathrm{T}$ (Group II) and below $20 \mu \mathrm{T}$ (Group III) are represented with pink, purple and yellow color, respectively. Samples from Group IV (gray bars) correspond to ambiguous paleomagnetic ages. 
Table 3. Summary of Accepted Studies for the Construction of a $16^{\circ} \mathrm{N}$ Reference Curve ${ }^{\mathrm{a}}$

\begin{tabular}{lllc}
\hline \multicolumn{1}{c}{ Authors } & \multicolumn{1}{c}{ Location } & \multicolumn{1}{c}{ Material } & No. Data \\
\hline Bowles et al. [2002] & California and Ecuador & pottery & 8 \\
Champion [1980] & Western United States & volcanic & 27 \\
Coe et al. [1978] & Hawaii & volcanic & 4 \\
Mankinen and Champion [1993] & Hawaii & volcanic & 22 \\
Pick and Tauxe [1993] & EPR south & volcanic glasses & 9 \\
Valet et al. [1998] & Hawaii & volcanic & 8 \\
\hline
\end{tabular}

${ }^{\mathrm{a}}$ See text for selection criteria.

estimation of worldwide paleointensity variations and therefore of first order (dipole) variations at the EPR $16^{\circ} \mathrm{N}$ site.

[28] The three normalized curves are presented on Figure $5 \mathrm{~b}$. Comparison between all sets reveals that the various types of data are broadly consistent and allow a first-order analysis of the paleointensity variations in the vicinity of the $16^{\circ} \mathrm{N}$ site using cross comparison analysis. Very low values between about 35,000 and 45,000 years

a)
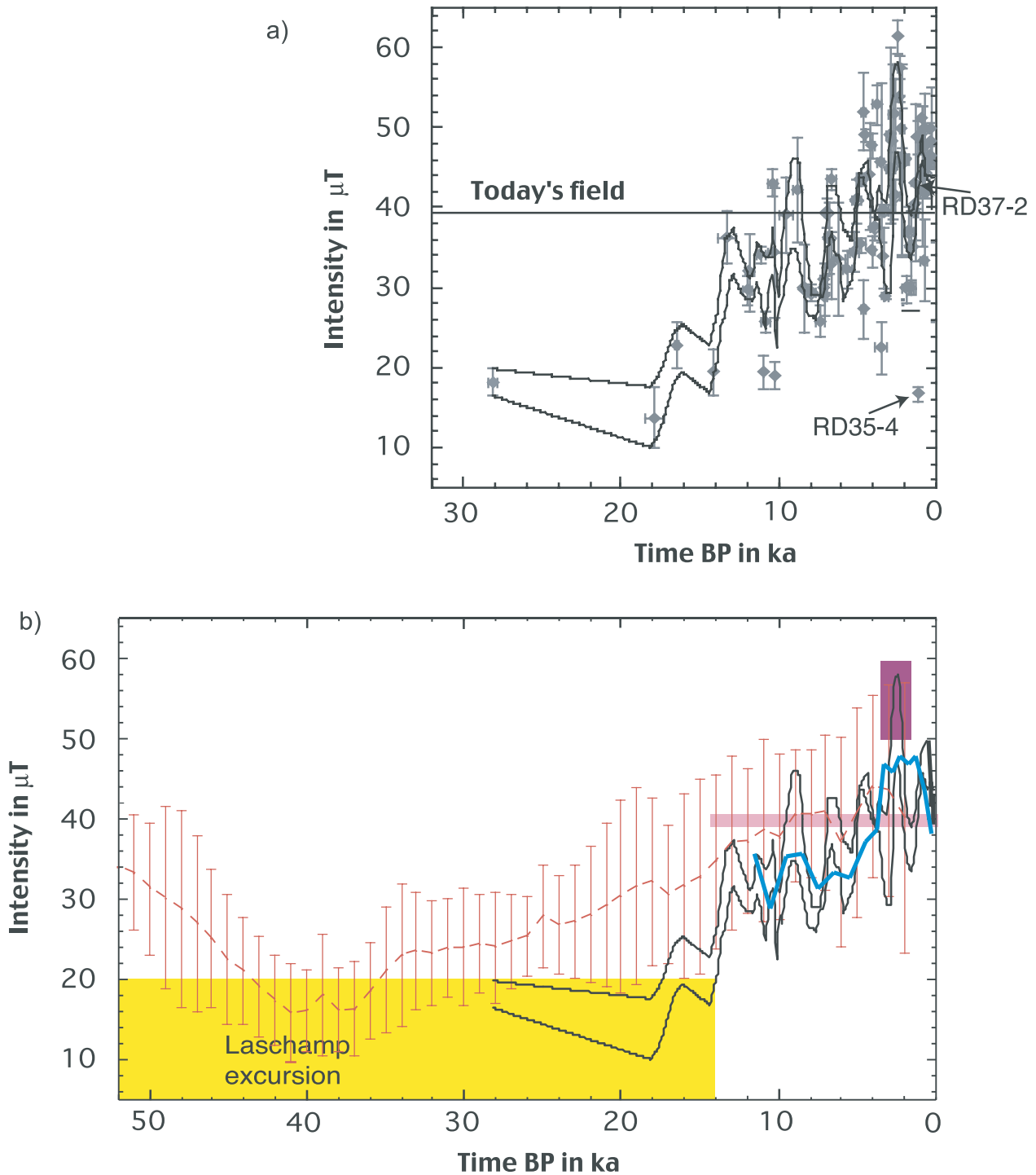

Figure 5. (a) Compilation of individual paleointensity estimates from selected published studies. Samples RD37-2 and RD35-4 [from Pick and Tauxe, 1993] are outlined as a typical example of possible incoherencies in this set. Also represented is the locally weighted least square " $16^{\circ} \mathrm{N}$ curve" constructed using the compilation. (b) Variations in paleointensity for the past $50 \mathrm{kyr}$ as given by the locally weighted " $16^{\circ} \mathrm{N}$ curve", the SINT-800 sedimentary stack (red curve with error bars) and the Yang et al. [2000] worldwide absolute data (blue curve, error bars are not represented for sake of clarity). All data were transformed from VADM to equivalent paleointensity at $16^{\circ} \mathrm{N}$ latitude site using the standard formulas [e.g., McElhinny and McFadden, 2000]. The paleointensity values associated with Group I, II and III are presented with the same color code as in Figure 4. 
RO3 segment
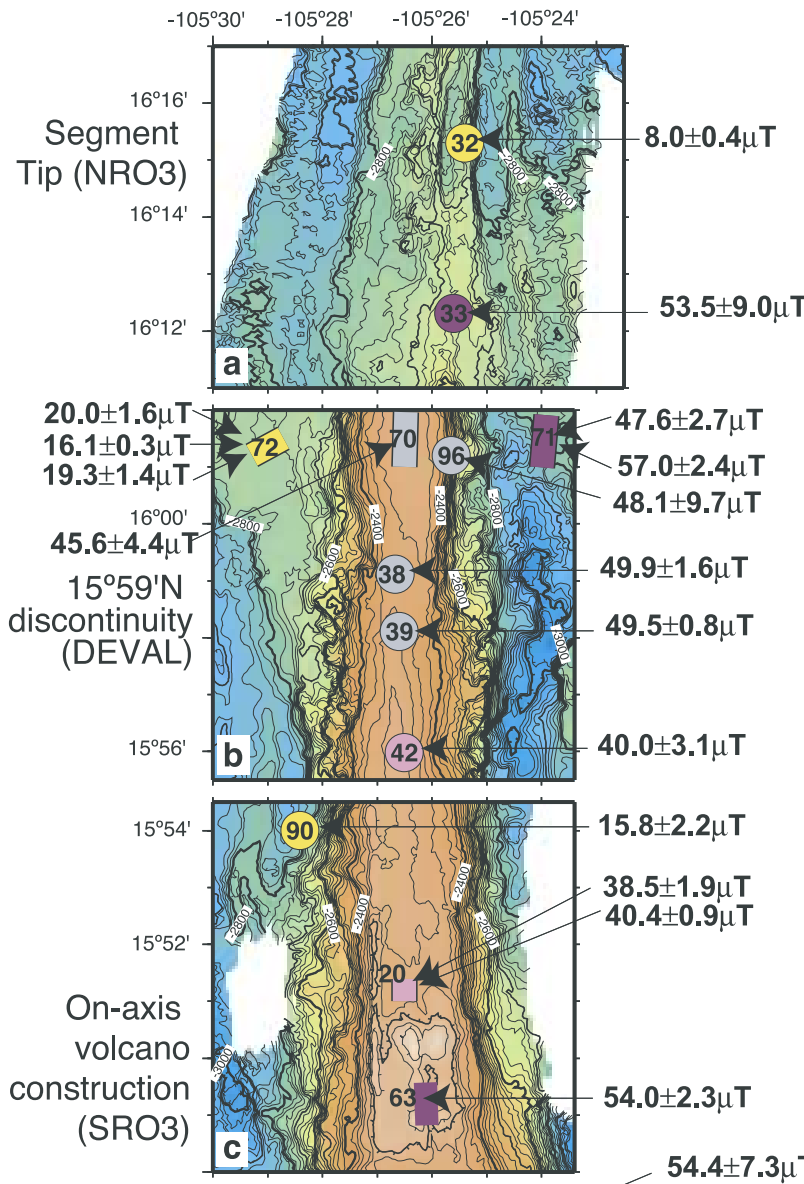

$47.6 \pm 2.7 \mu \mathrm{T}$

$57.0 \pm 2.4 \mu \mathrm{T}$ $48.1 \pm 9.7 \mu \mathrm{T}$

$49.9 \pm 1.6 \mu \mathrm{T}$

$49.5 \pm 0.8 \mu \mathrm{T}$

$40.0 \pm 3.1 \mu \top$

$15.8 \pm 2.2 \mu \mathrm{T}$

$38.5 \pm 1.9 \mu \mathrm{T}$

$40.4 \pm 0.9 \mu \mathrm{T}$

$54.0 \pm 2.3 \mu T$

$54.4 \pm 7.3 \mu \mathrm{\top}$ $54.4 \pm 2.0 \mu \mathrm{T}$
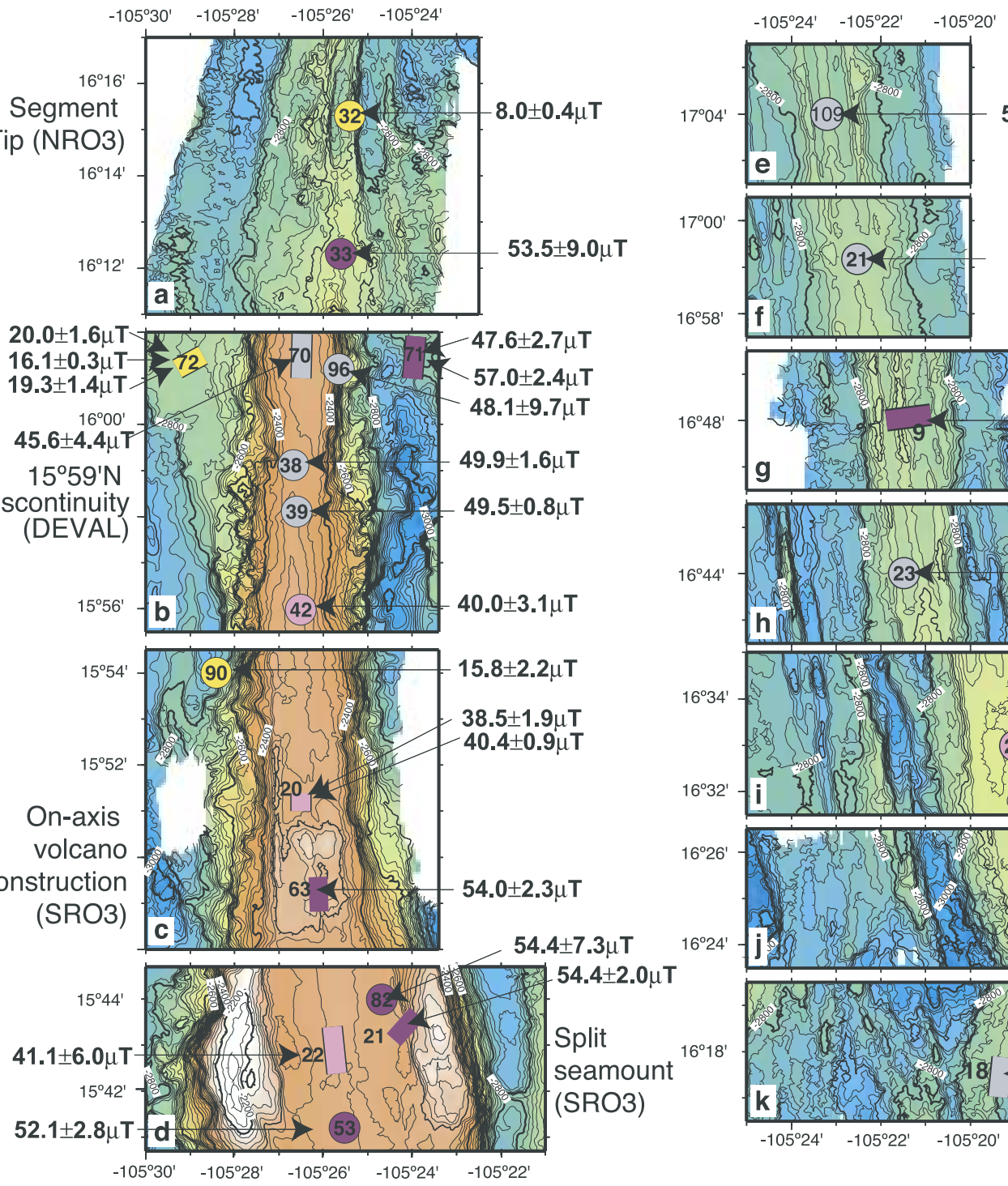

$50.0 \pm 2.5 \mu \mathrm{T}$

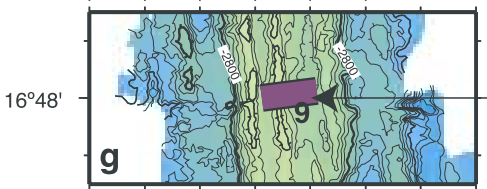

$55.1 \pm 1.5 \mu \mathrm{T}$

Depth $(m)$
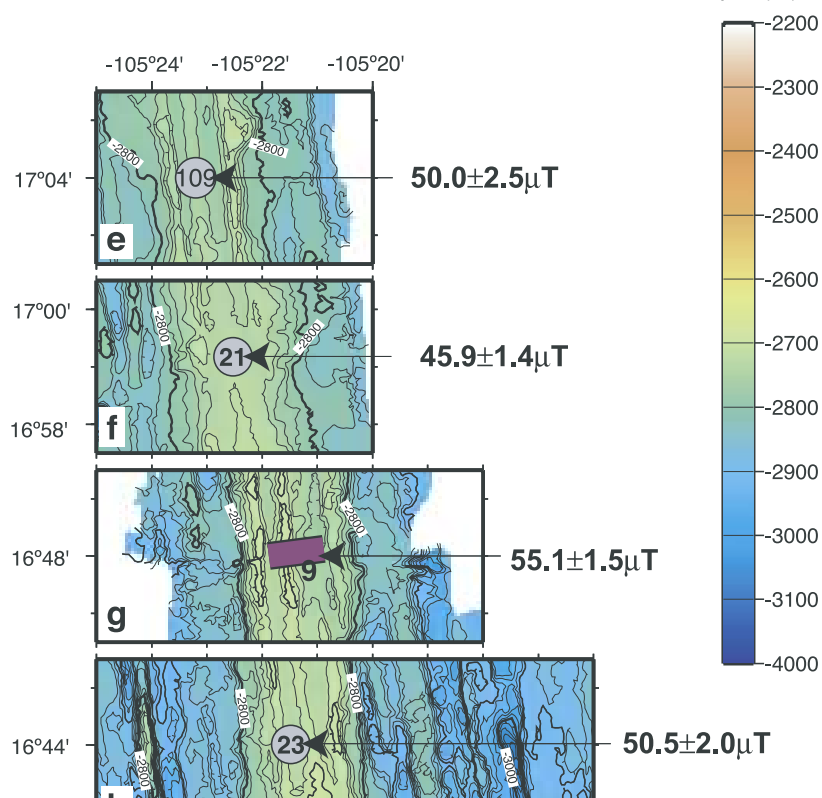

$50.5 \pm 2.0 \mu \mathrm{T}$

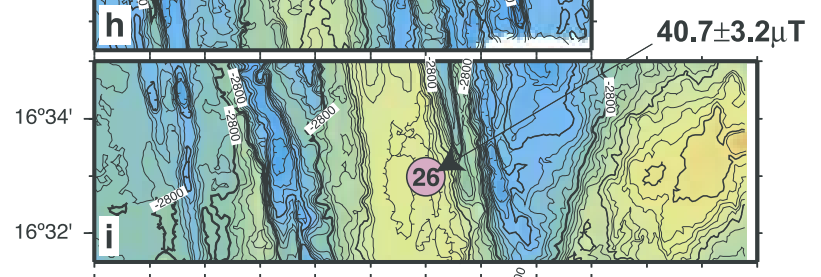

$16^{\circ} 26^{\prime}$

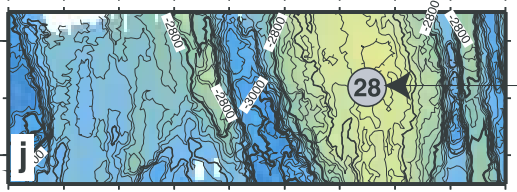

48.5 $\pm 5.0 \mu \mathrm{T}$

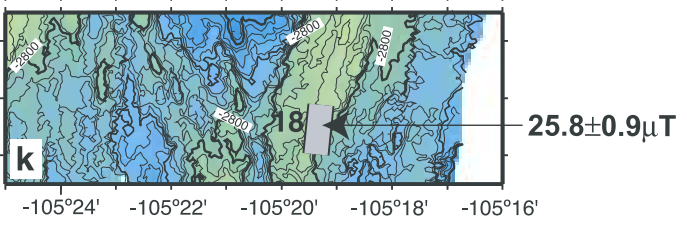

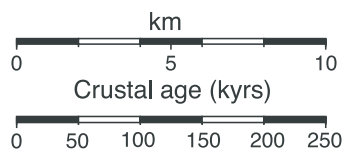

Figure 6. Detailed morphology of the ridge axis for the various sample locations along the R03 segment (left) and the R02 segment (right). Contour interval is $20 \mathrm{~m}$. The scale for crustal ages assumes a mean half-spreading rate of $40 \mathrm{~mm} / \mathrm{yr}$. Locations of samples are represented as lines for dredges and circles for rock cores. Paleointensity values are given and color labels make use of the same conventions as in Figures 4 and 5 and indicate samples belonging to paleointensity age group I (pink), group II (purple), group III (gray) and group IV (yellow) (see text for details).

B.P. can be identified using the sedimentary records as linked to the well-known period of worldwide instability of the Earth's magnetic field corresponding to the Laschamp geomagnetic excursion [e.g., Chauvin et al., 1989; Kent et al., 2002]. This intensity low is followed by a general increase until a maximum, probably best defined by the numerous data on the absolute curves, is reached at about $2-3 \mathrm{ka}$; then there is a decrease which is clearly seen in the $16^{\circ} \mathrm{N}$ curve until $\sim 1$ ka followed by a short recovery of strength and a new decrease toward present-day values.

\section{Discussion: Timing of Volcanism Along the Northern EPR}

[29] Estimates of paleointensity variations for the northern EPR (Figure 5b) provide a basis to link the 
Table 4. Summary of Samples Associated With a "Paleointensity" Group"

\begin{tabular}{|c|c|c|c|c|c|c|c|}
\hline Sample & Location & $\begin{array}{c}\mathrm{F}_{\text {tot }} \text { and } 2 \sigma, \\
\mu \mathrm{T}\end{array}$ & $\begin{array}{l}\text { Paleointensity } \\
\text { Group }\end{array}$ & $\begin{array}{c}\text { Pmag } \\
\text { Age, ka }\end{array}$ & $\begin{array}{l}\text { Crustal } \\
\text { Age, ka }\end{array}$ & Shipboard Description & $\begin{array}{l}\text { Geochemical } \\
\text { Group }\end{array}$ \\
\hline \multicolumn{8}{|c|}{ Rock Core } \\
\hline 53 & 15.69 & $52.1 \pm 2.8$ & II & $2 \pm 1$ & 0 & N.A. & $\mathrm{SRO} 3$ \\
\hline 82 & 15.73 & $54.4 \pm 7.3$ & II & $2 \pm 1$ & 45 & N.A. & SR03 \\
\hline 90 & 15.90 & $15.8 \pm 2.2$ & III & $>10$ & 85 & $\begin{array}{l}\text { "Sediment cover and } \\
\text { some fresh glasses" }\end{array}$ & SR03 \\
\hline 42 & 15.93 & $40.0 \pm 3.1$ & I & Contemp.? & 0 & "Extremely fresh glasses" & SR03 \\
\hline 33 & 16.21 & $53.5 \pm 9$ & II & $2 \pm 1$ & 0 & "Mildly fresh glasses" & $\mathrm{RO} 2$ \\
\hline 32 & 16.25 & $8.0 \pm 0.4$ & III & $>10$ (40?) & ambiguous (see text) & $\begin{array}{l}\text { "Fresh glass within } \\
\text { thin Mn coatings } \\
\text { sediments" }\end{array}$ & R02 \\
\hline 26 & 16.55 & $40.7 \pm 3.2$ & I & Contemp.? & 15 & N.A. & $\mathrm{RO} 2$ \\
\hline \multicolumn{8}{|c|}{ Dredge } \\
\hline $22-7$ & 15.71 & $41.1 \pm 6.0$ & I & Contemp.? & 0 ? & $\begin{array}{l}\text { "Beautiful pristine } \\
\text { chips only } 1-2 \\
\text { chips show Mn } \\
\text { alteration" }\end{array}$ & NP \\
\hline $21-3$ & 15.72 & $54.4 \pm 2.0$ & II & $2 \pm 1$ & $60-80$ & $\begin{array}{l}\text { "Some Mn coating, } \\
\text { patchy with lots } \\
\text { of fresh glasses" }\end{array}$ & SRO3 \\
\hline $63-1$ & 15.82 & $54.0 \pm 2.3$ & II & $2 \pm 1$ & 0 & N.A. & SRO3 \\
\hline $20-1$ & 15.85 & $38.5 \pm 1.9$ & I & Contemp.? & 5 & $\begin{array}{l}\text { "No sediment - not very altered, } \\
\text { some patchy Mn } \\
\text { coating on fractures" }\end{array}$ & NP \\
\hline $20-7$ & 15.85 & $40.4 \pm 0.9$ & I & Contemp.? & 5 & Idem $20-1$ & NP \\
\hline $71-1$ & 16.02 & $57 \pm 2.4$ & II & $2 \pm 1$ & $110-120$ & $\begin{array}{l}\text { "Off axis dredge } \\
\text { which contains } \\
\text { amazingly fresh } \\
\text { material" }\end{array}$ & SRO3 \\
\hline $72-5$ & 16.02 & $20 \pm 1.6$ & III & $>10$ & $100-120$ & N.A. & $\mathrm{SRO} 3$ \\
\hline $72-2$ & 16.02 & $19.3 \pm 1.4$ & III & $>10$ & $100-120$ & $\begin{array}{l}\text { " } 50 \% \text { of surface } \\
\text { with Mn coating", }\end{array}$ & SRO3 \\
\hline $72-3$ & 16.02 & $16.1 \pm 0.3$ & III & $>10$ & $100-120$ & "Alterated glasses" & SRO3 \\
\hline $9-8$ & 16.80 & $55.1 \pm 1.5$ & II & $2 \pm 1$ & $0-20$ & $\begin{array}{l}\text { "Palagonized glass } \\
\text { on outer surface, } \\
\text { moderate Mn staining" }\end{array}$ & $\mathrm{RO} 2$ \\
\hline
\end{tabular}

${ }^{a}$ Definitions are as follows: $F_{\text {tot }}$ and $2 \sigma$, paleointensity results and corresponding $95 \%$ standard error (in $\mu \mathrm{T}$ ), Pmag age, probable age inferred from paleointensity. Crustal ages are based on distance from morphological ridge assuming a half-spreading rate of $40 \mathrm{~m} / \mathrm{kyr}$ (rounded to nearest $5 \mathrm{ka}$ ). Shipboard descriptions taken from ship log when available. Geochemical groups are as follows: SRO3 (NR03) refers to the chemical signature typifying segment R03 south (north) of the $15^{\circ} 59^{\prime} \mathrm{N}$ DEVAL; RO2 is the signature associated with the segment north of the $16^{\circ} 20^{\prime} \mathrm{N}$ OSC; and NP denotes New Pulse compositions (see Donnelly [2002] for details).

paleomagnetic measurements obtained on the $16^{\circ}-17^{\circ} \mathrm{N}$ lava samples with past values of the geomagnetic field. Considering the uncertainties in the reference curves, lava samples are conservatively classified according to four age groups.

[30] Group I consists of dredges 20 and 22, rock cores 26 and 42 and corresponds to paleointensities ranging from 38.5 to $41.1 \mu \mathrm{T}$, very close to present values for the study area $(\sim 39 \mu \mathrm{T})$. Samples from this group could have erupted during the past few decades, but they could also correspond to flows of several hundreds years old or more as shown by the curves in Figure 5b.

[31] Group II includes dredges 9, 21, 63 and 71, and rock cores 33,53 and 82 , which all have paleointensities clustering above $52 \mu \mathrm{T}$, corresponding to the only documented peak in intensity for the past $50 \mathrm{kyr}$, which occurred 2000 3000 years ago (see Figure 5b).

[32] Group III, which includes dredge 72 and rock cores 32 and 90 corresponds to low paleointensities, less than half of today's value, which is a persistent characteristic of the geomagnetic field prior to $\sim 15,000$ years B.P. (keeping in mind that there might be unresolved variations of the field in early Holocene see Figure 5b).

[33] Group IV includes the remaining units, i.e., dredges 18 and 70 and rock cores 21, 23, 28, 38, 39, 96 and 109, and corresponds to intermediate values, ranging between 45.6 and $50.5 \mu \mathrm{T}$ (with the exception of dredge 18 which is associated with a value of $25.8 \mu \mathrm{T}$ ). The paleointensity values from these units provide ambiguous age relations: the lavas are not contemporaneous but could have erupted either a few centuries or a few millennia ago.

[34] Paleointensity intervals for Groups I, II and III are indicated on Figure 5b with pink, purple and yellow colors, respectively, to indicate the age constraints. The same color code is used to locate samples from these groups on Figures 4 and 6, where the precise location and the mean paleointensity value of the samples are reported.

[35] The ages inferred from the paleointensity correspond well with characteristics of the samples. The sample characteristics relate to the freshness of the rocks recovered in the dredge hauls or the glasses recovered in the rock cores (see summary in Table 4). Samples from Group I were 
systematically described at sea in the expedition log book as having "extremely fresh glass," "beautiful pristine glass," or "glass with only patchy Mn coating," arguing in favor of a contemporaneous eruption. Samples from Group II were described as having "mildly fresh glass," "some patchy Mn coating," "palagonized glass, moderate Mn staining." Samples from Group III, which we infer are the oldest, were described as "slightly altered" or "moderately fresh." The samples from Group IV with the ambiguous paleointensity ages have variable visual descriptions that correspond to those of either Group I or Group II. Hence, if glasses with patchy Mn coating and/or palagonization could be considered characteristics of lavas 2000-3000 years old, the age ambiguity inherent to Group IV samples might be tentatively lifted in some cases. Sample RC28, described as "extremely fresh glass," sample RC21, described as "lots of fresh glass," and sample RC109, described as "perfectly fresh glass," may therefore date from a few centuries rather than a few millennia. On the other hand, samples described as having Mn coatings might be a few millennia old.

[36] These qualitative descriptions based on the appearance of the samples are confirmed for the rock cores by the amount of sediment recovered. The rock cores have central holes to recover any sediment that is present. The youngest lava flows are expected to have virtually no sediment cover, while those many thousands of years old can be expected to be covered by a few centimeters of sediment, leading to the recovery of sediment with the glass. Indeed, Group I and II rock cores recovered no sediment whatever. Group III rock cores recovered "lots of sediment," Group IV had either no sediment or very small amounts; this may correspond to the two possible ages of this group of samples.

[37] The combination of magnetic data, sample freshness and sediment recovery thus gives some confidence with respect to the age determinations of the samples (see Table 4). A general conclusion is that the eruption age of the sample does not generally correspond with the "crustal age" determined by distance from the center of the ridge axis. This is simply because lava flows spread out from the central fissure and are distributed over a variety of distances from the "zero age" point. In the following, we examine the ages with respect to the local character of axial morphologies, and derive a self-consistent scenario for the timing of volcanism along the $\mathrm{RO} 2$ and $\mathrm{RO} 3$ ridge segments.

\subsection{Volcanism Along the Anomalous Southern Ridge Segment (RO3)}

[38] The RO3 segment is unique for the shallow depth and broad width of its summit plateau (Figures 1, 6a, 6b, $6 \mathrm{c}$, and $6 \mathrm{~d}$ ). This plateau is $2300-2350 \mathrm{~m}$ deep and up to $6 \mathrm{~km}$ wide, while typical values for the northern EPR are $2500-2700 \mathrm{~m}$ and $0.5-2 \mathrm{~km}$, respectively. The pronounced spreading asymmetry across that segment and the presence of an axis-parallel ridge $10 \mathrm{~km}$ east of the present EPR are consistent with a westward jump of the axis of accretion of several kilometers some 100,000 years ago, toward the prominent P1545 volcanic ridge [Weiland and Macdonald, 1996]. The broad axial plateau at $15^{\circ} 38^{\prime}-$ $47^{\prime} \mathrm{N}$ is bounded on each side by a hemispherical construct (Figure 6d), suggesting that the new ridge localized on a near-axis seamount, effectively bisecting the edifice in two matching halves. A subtle $2 \mathrm{~km}$ right-lateral offset of the axis of accretion at $15^{\circ} 59^{\prime} \mathrm{N}$ corresponds to a "DEVAL", according to the terminology of Langmuir et al. [1986; see also Macdonald et al., 1992; Langmuir et al., 1998] (Figure 6b). Coinciding with that DEVAL is a right-lateral step in the axial melt lens mapped with seismic methods [Carbotte et al., 2000], and a discrete change in chemistry for lavas on-axis [Donnelly, 2002] (Figure 7), suggesting that the DEVAL reflects a magmatic segmentation beneath this segment. As a result, Donnelly [2002] subdivided this segment into subsegments SRO3 and NRO3, corresponding to south and north of the $15^{\circ} 59^{\prime} \mathrm{N}$ DEVAL, respectively.

[39] The chemistry of lavas from RO3 segment suggests that there are three different magma sources feeding this segment. Chemical parameters such as $\mathrm{K}_{2} \mathrm{O} / \mathrm{TiO}_{2}$ and/or radiogenic isotopes such as ${ }^{87} \mathrm{Sr} /{ }^{86} \mathrm{Sr}$ are good indicators of different sources. The $15^{\circ} 59^{\prime} \mathrm{N}$ DEVAL marks an abrupt and discrete change in both $\mathrm{K}_{2} \mathrm{O} / \mathrm{TiO}_{2}$ (Figure 7) and ${ }^{87} \mathrm{Sr} /{ }^{86} \mathrm{Sr}$ for lavas along the broad axial high. South of the DEVAL, SRO3 samples have $\mathrm{K}_{2} \mathrm{O} / \mathrm{TiO}_{2} \geq 0.15$ and average ${ }^{87} \mathrm{Sr} /{ }^{86} \mathrm{Sr}(0.70284)$ whereas north of the DEVAL, NRO3 samples have lower $\mathrm{K}_{2} \mathrm{O} / \mathrm{TiO}_{2}(0.13)$ and lower average ${ }^{87} \mathrm{Sr} /{ }^{86} \mathrm{Sr}$ (0.70267). The overall distinction between SRO3 and NRO3 lava compositions is complicated by the presence of a third distinct magma composition, referred to as New Pulse [Langmuir et al., 1998; Donnelly, 2002]. This composition is only found south of the DEVAL. While its $\mathrm{K}_{2} \mathrm{O} / \mathrm{TiO}_{2}$ values are similar to NRO3 samples (i.e., $<0.15$; see Figure 7), its isotope composition clearly shows it requires a distinct source than that feeding NRO3 with New Pulse samples having much higher ${ }^{87} \mathrm{Sr} /{ }^{86} \mathrm{Sr}(\sim 0.70303)$ and a unique $\mathrm{Pb}$ isotope composition [Donnelly, 2002]. Because New Pulse lavas solely occur within a few $100 \mathrm{~m}$ from the ridge axis and because of their fresh physical appearance, they are interpreted to be a recent injection [Langmuir et al., 1998; Donnelly, 2002]. Outside of the appearance of New Pulse lavas on SRO3, both NRO3 and SRO3 show remarkably uniform compositions.

[40] Lavas that occur off the broad axial high and near the OSC at the segment ends show greater variations in chemistry. The off-axis lavas have similar chemical characteristics to SRO3 samples (excluding New Pulse) with $\mathrm{K}_{2} \mathrm{O} / \mathrm{TiO}_{2} \geq 0.15$ and ${ }^{87} \mathrm{Sr} /{ }^{86} \mathrm{Sr} \sim 0.70286$. Near the segment ends samples become increasingly fractionated [Donnelly, 2002]. Theses samples near segment ends are discussed separately below.

[41] The four samples compatible with contemporary paleointensities (Group I) were all collected within a few hundred meters of the morphological axis of accretion. Samples associated with the "New Pulse" compositions (D20-1, D20-7 and D22-7) all belong to Group I, confirming the interpretation of the recent eruption of this composition. The fourth sample, RC42, is located toward the northern end of subsegment SRO3 and has a composition typical for that segment [Donnelly, 2002]. This indicates that the injection of New Pulse lavas is presently restricted to the central portion of subsegment SRO3.

[42] All other samples collected across and along the axial high display higher paleointensities than Group I. Most of them are characteristic of eruptive ages 20003000 years B.P. (Group II); the only exception (which is 


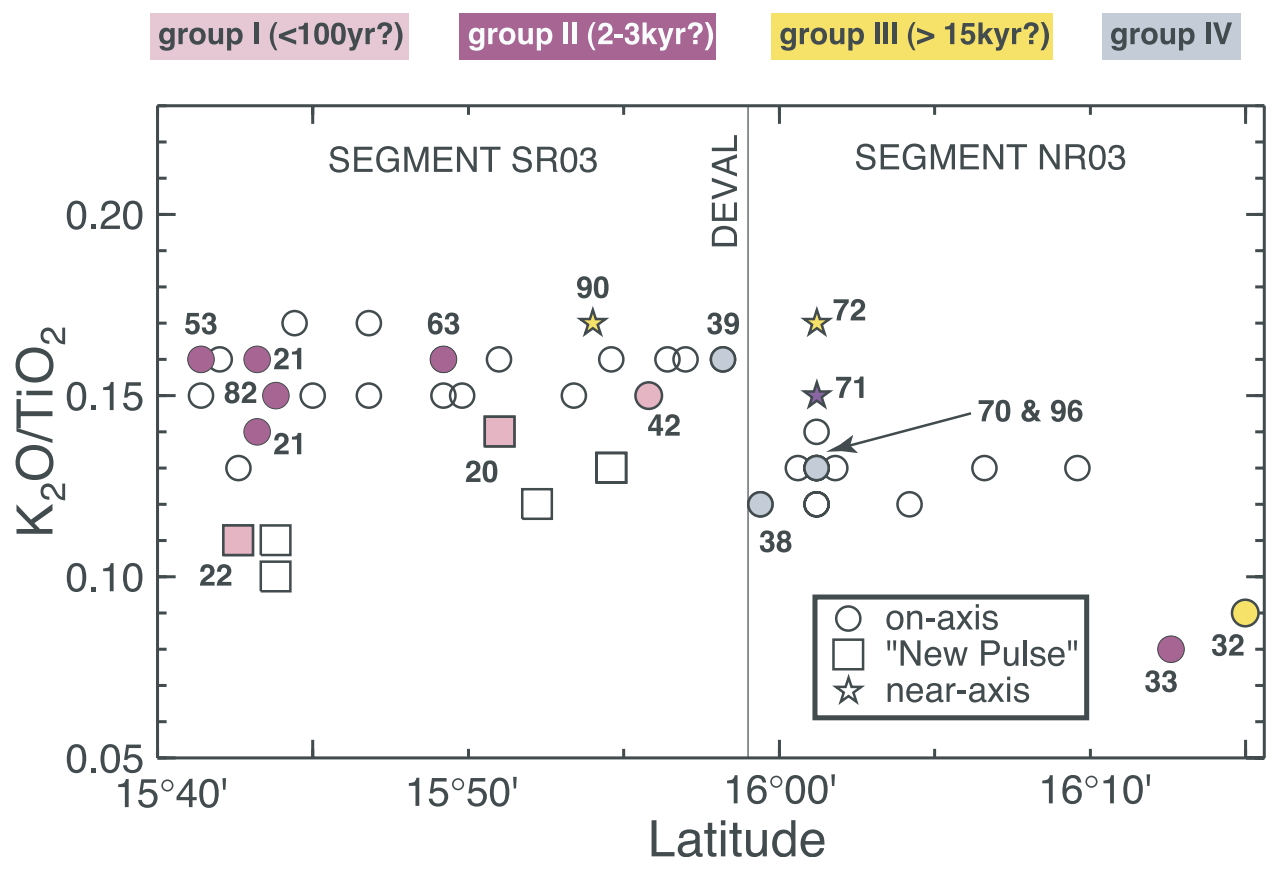

Figure 7. Geochemical variations of samples collected along the R03 ridge segment [after Donnelly, 2002]. Samples that have been analyzed for paleointensities are color-coded according to their age group, applying the same convention as in Figures 4, 5, and 6. The different symbols refer to the spatial and chemical characteristics of the samples. The vertical line marks the location of the $15^{\circ} 59^{\prime} \mathrm{N}$ "DEVAL" that defines subsegments SR03 and NR03. This 2-km-wide axial discontinuity also corresponds to a clear boundary with respect to major and trace elements as well as isotopes [Donnelly, 2002]. K2O/TiO2 values higher than 0.15 , as are present along segment SR03, are usually interpreted to indicate enriched basalts (E-MORB). Note that along SR03, "New Pulse" compositions (squares) and enriched compositions (circles) tend to map in distinct age groups (Group I and II, respectively.)

discussed below) is sample RC32, from the very northern tip of the ridge segment, belonging to Group III. The tight grouping of paleointensity values of Group II samples (Figure 4) further suggests that lavas were emplaced over a short timescale. These samples were collected at the edge of the broad summit plateau (see red dots and lines in Figures $6 a, 6 c$, and $6 \mathrm{~d}$ ) on 50-75 ka old oceanic crust (D21-3 and RC82), or very close to the axis of accretion (D63, RC33, and RC53). They also include sample D71-1 collected at the base of the axial high on $120 \mathrm{ka}$ old oceanic crust. Interestingly, although that sample is located north of the $15^{\circ} 59^{\prime} \mathrm{N}$ DEVAL, it has the same chemical composition as axial samples collected south of the DEVAL along subsegment SRO3 [Donnelly, 2002]. We interpret this broad distribution of Group II lavas over the RO3 segment as resulting from a phase of intense volcanic activity at 2000 3000 years B.P., when erupted lavas flooded the entire width of the axial plateau as well as its flanks. This interpretation is consistent with the uniformly reflective character of the entire axial high in side-scan sonar imagery [Weiland and Macdonald, 1996] and is confirmed by the very low levels of sediment recovery. The occurrence of Group II lavas very close to the present axis of accretion further suggests that lavas erupted since that intense volcanic episode have generally not extended beyond a few hundred meters from their source. Hence the most recent volcanic activity along the RO3 segment seems to be characterized by small volume eruptions.
[43] Axial samples RC38 and RC39 bracket the $15^{\circ} 59^{\prime} \mathrm{N}$ DEVAL that offsets the axis by $2 \mathrm{~km}$. RC38 and RC39 have distinct compositions characteristic of segments $\mathrm{NRO} 3$ and SRO3, respectively (Figure 7). Hence, although these samples have identical paleointensity values characteristic of the ambiguous Group IV, they presumably must nonetheless belong to separate lava flows. Neither of these rock cores recovered significant sediment, and hence the chemical discontinuity at the DEVAL appears to be a young feature.

[44] Samples RC90, D72-1, D72-2 and D72-3 are classified with the older (low intensity) Group III, consistent with their locations at the base of the axial high on seafloor with an estimated crustal age of 100-110 ka. The three samples from Dredge 72 all yield almost the same paleointensity value and can be considered coeval on the timescale of the Earth's magnetic field variations. This is consistent with eruptions within a few tens of years sometime before 15 ka ago.

\subsection{Volcanism Along “Typical” RO2 Ridge Segment}

[45] The RO2 ridge segment displays a morphology characteristic of intermediate spreading rates. Its summit is rifted with a trough 20-50-m-deep and 2-3-km-wide (Figure 6). Pervasive faulting across that summit trough is inferred from the unusually high level of hydrothermal activity [Baker et al., 2001]. An elongated feature $\sim 20 \mathrm{~m}$ high and $\sim 200$-m-wide occupies the axis of the trough and is interpreted as a volcanic ridge marking the axis of 
accretion (Figures $6 \mathrm{e}$ to $6 \mathrm{k}$ ). At $16^{\circ} 24^{\prime}-16^{\circ} 35^{\prime} \mathrm{N}$ and $16^{\circ} 48^{\prime}-17^{\circ} 00^{\prime} \mathrm{N}$, the summit trough almost disappears beneath what appear to be volcanic constructions, and enhanced volcanism is inferred for these two locations. Accordingly, a seamount exists near $16^{\circ} 33^{\prime} \mathrm{N}$ close to the ridge axis, and a seismic reflector interpreted as the top of an axial magma chamber is detected between $16^{\circ} 20^{\prime}$ and $16^{\circ} 36^{\prime} \mathrm{N}$ [Carbotte et al., 2000]. Unfortunately, seismic profiling did not extend along-axis north of $16^{\circ} 48^{\prime} \mathrm{N}$, as far as the other obtrusion of the rifted crest.

[46] Unlike on segment RO3, there does not appear to be a systematic geographic distribution of lava compositions on segment $\mathrm{RO} 2$. $\mathrm{RO} 2$ lavas have even lower $\mathrm{K}_{2} \mathrm{O} / \mathrm{TiO}_{2}$ $(<0.10)$ and lower ${ }^{87} \mathrm{Sr} /{ }^{86} \mathrm{Sr}(0.70259)$ than $\mathrm{NRO} 3$, arguing that the $16^{\circ} 20^{\prime} \mathrm{N}$ OSC represents another magmatic segmentation [Donnelly, 2002].

[47] Most of the samples from this segment have paleointensity values from the ambiguous Group IV, and only two samples are associated with Group I and II. Sample RC26, collected at $16^{\circ} 33^{\prime} \mathrm{N}$ where the axis is filled with a volcanic construct, has a paleointensity value compatible with a contemporary eruption (Group I). This is in good agreement with the presumed enhanced volcanic activity at that location. Sample D9-8 belongs to Group II and is therefore probably 2000-3000 years old. Unlike observations at segment RO3, no clustering of paleointensity values was found. Instead, the dispersion of results would argue in favor of smaller magmatic events dispersed in time. Further insights can be drawn regarding Group IV samples RC21, $\mathrm{RC} 28$ and RC109 by examining the paleointensity values in combination with shipboard sample descriptions. As discussed above, all three samples were independently described as having extremely fresh glass and there was no sediment recovery. They are thus probably just a few centuries rather than a few millennia old. That interpretation is consistent with the presumed renewed volcanism in the neighborhood of samples RC21 and RC28, and with the fact that RC109 was collected on top of the narrow axial volcanic ridge. Hence we propose the following scenario of the volcanic activity along segment RO2. Volcanic activity was generally focused along the narrow volcanic ridge marking the axis of the trough. Near $16^{\circ} 24^{\prime}-16^{\circ} 35^{\prime} \mathrm{N}$ and $16^{\circ} 48^{\prime}-17^{\circ} 00^{\prime} \mathrm{N}$, volcanic activity probably extended across the entire width of the filled trough. The shipboard description of glasses from sample RC23, collected away from the two areas of renewed volcanism and at the western edge of the summit trough, indicates "filmy palagonite on many surfaces" and there was also sediment recovered. Hence its paleointensity value of $50 \mu \mathrm{T}$ may indicate an age of a few thousand years rather than a few centuries.

\subsection{Volcanism Near Segment Ends}

[48] The lowest paleointensity values measured on axial samples occur at the tips of the $\mathrm{RO} 3$ and the $\mathrm{RO} 2$ segments which define the $16^{\circ} 20^{\prime} \mathrm{N}$ OSC (Figures 6a and 6k). Sample $\mathrm{RC} 32$ has a very low intensity value of $8 \mu \mathrm{T}$. Such low values are typical of periods of instabilities of the geomagnetic field during excursions or reversals [e.g., Carlut et al., 1999]. The only known excursion within the last $50 \mathrm{kyr}$ is the Laschamp excursion, dated between 35 and $50 \mathrm{ka}$ [Gillot et al., 1979; Chauvin et al., 1989; Kent et al., 2002]. Collection of oriented samples from the RC32 lava flow would constrain the direction of the field at the time of eruption and verify whether it was emplaced during the Laschamp excursion. Sample D18 $(25.8 \mu \mathrm{T})$ is at least several thousands years old. These rather old ages for samples collected at the axis of the EPR are consistent with a presumably reduced magma supply at large OSCs, where crustal accretion becomes distributed between two spreading ridges [Macdonald, 1998]. The unusually old lava collected at the tip of the RO3 segment (RC32) may indicate that this ridge tip was abandoned by a "self-decapitation" mechanism [Macdonald et al., 1987], whereby the new ridge axis cuts inside or outside of itself and rafts off the abandoned ridge tip on the flank. The active tip of the $16^{\circ} \mathrm{N}$ segment may actually be located on the curved feature $0.5 \mathrm{~km}$ west of sample RC32 (Figure 6a). That feature extends directly north of the remaining segment whereas the ridge tip on which sample RC32 is located appears to have been rafted inside the overlapped region. The $500 \mathrm{~m}$ spacing between the two curved ridges suggest a difference in crustal age of at least $\sim 12 \mathrm{ka}$, compatible with the minimum paleomagnetic age of sample RC32.

\section{Conclusion}

[49] Successful paleointensity analyses were obtained on 63 submarine basaltic samples from 27 MORB units collected along two segments on the EPR ( $\mathrm{RO} 2$ and $\mathrm{RO} 3$ ). Most results were obtained from the analysis of submarine basaltic glass (SBG) fragments. Our study does not specifically address the problem of possible chemical remagnetization in several million year old SBG (see the recent papers by Heller et al. [2002] and Smirnov and Tarduno [2003]) but the high paleointensity values obtained on the majority of the samples analyzed here make a case for original thermoremanent magnetization in "young" SBG of a few tens of thousands years old. Furthermore, the outermost cryptocrystalline sample when analyzed with its glassy counterpart does not exhibit a systematic bias as was feared [see Carlut and Kent, 2002]. While this increases our confidence in paleointensity values obtained on glasses, measurements on the cryptocrystalline part of samples should only be used with caution due to the very strong, and still not well understood, bias in paleointensity values found in the inner, crystalline part of MORB samples [Carlut and Kent, 2002; Tauxe and Love, 2003].

[50] It has been proposed that paleointensities can be used as a tool to help our comprehension of the volcanic history of ridge segments (see in particular Carlut and Kent [2000] and Gee et al. [2000]). For this purpose the compilation of an accurate reference curve is mandatory. The most relevant data set to our study is paleointensity data obtained from welldated SBG, lavas or archeological artifacts in the vicinity of the EPR. Unfortunately, the presence of outliers and the paucity of data especially prior to the last 10,000 years only allow a first-order analysis and underscore the need for much better constrained new data. Nevertheless, we present a compilation of absolute data specifically adapted to the EPR around the $16^{\circ} \mathrm{N}$ latitude. With the addition of data from the global compilation of Yang et al. [2000] and the sedimentary stack of Guyodo and Valet [1999], we can place samples in age categories on the basis of their paleointensity values in conjunction with sample descriptions and petrolog- 
ical data. We thus propose the following volcanic history for both the $\mathrm{RO} 2$ and the $\mathrm{RO} 3$ ridge segments.

[51] The broad distribution of lavas with a paleointensity value clustering around $55 \mu \mathrm{T}$ over the RO3 segment is interpreted as resulting from a phase of intense volcanic activity at 2000-3000 years B.P., when lavas flooded the entire width of the axial plateau as well as its flanks. In contrast, the RO2 segment is characterized by the absence of "clustering" in paleointensity values, which we interpret to reflect smaller eruptive events during the last few thousands years. Samples with paleointensities associated with today's value $(39 \mu \mathrm{T})$ only occur along the axis of the inflated RO3 segment and also along the RO2 segment where the summit trough is filled with volcanic constructs.

[52] The combined data suggest a marked episodicity in EPR magmatism. Recent volcanism is restricted to small flows at the very center of the ridge axis. In the past, an outpouring of volcanism over a limited period of time covered a substantial width of the East Pacific Rise in this region.

[53] Samples associated with a low paleointensity value, on the order of half of today's value or less, are at least a few ka old given the paleointensity reference curves and are systematically located off-axis but also at segment ends. This last location is compatible with a generally reduced magmatism near segment ends. Of course, young lava flows must occur at segment ends as well as at segment centers in order to create the crust of relatively uniform thickness along the EPR; the perspective from these data, however, is that the centers of segments tend to have younger flows compared to the ends of segments.

[54] The consistent relation between the apparent freshness of the basaltic glasses, their petrological signature, location and paleomagnetic ages increase our confidence in the accuracy and potential of the paleointensity method applied to young SBG. This study demonstrates that paleointensity can be used as a standard tool to help constrain volcanic history at ridge axes. Further progress to understand the timing of volcanism along the EPR could be made with a strategy combining detailed near-bottom investigation, petrological studies and paleomagnetic methods.

[55] Acknowledgments. We thank Jeff Gee and two anonymous reviewers for their careful and constructive reviews. Grant NSF-OCE 0002563 and the CNRS funded this research. Samples were collected during expedition PANR01MV of the R/V Melville, which was jointly led by C. Langmuir, J. Bender, and S. Shirey. Some figures were produced with GMT software package [Wessel and Smith, 1998]. This is Lamont-Doherty Earth Observatory contribution 6535.

\section{References}

Auzende, J.-M., et al. (1996), Recent tectonic, magmatic, and hydrothermal activity on the East Pacific Rise between $17^{\circ} \mathrm{S}$ and $19^{\circ} \mathrm{S}$ : Submersible observations, J. Geophys. Res., 101(B8), 17,995-18,010.

Baker, E. T., M.-H. Cormier, C. H. Langmuir, and K. Zavala (2001), Hydrothermal plumes along segments of contrasting magmatic influence, $15^{\circ} 20^{\prime}-18^{\circ} 30^{\prime} \mathrm{N}$, East Pacific Rise: Influence of axial faulting, Geochem. Geophys. Geosyst., 2(9), doi:10.1029/2000GC000165.

Bowles, J., J. S. Gee, J. Hildebrand, and L. Tauxe (2002), Archaeomagnetic intensity results for California and Ecuador: Evaluation of regional data, Earth Planet. Sci. Lett., 203, 967-981.

Carbotte, S. M., A. Solomon, and G. J. Ponce-Correa (2000), Evaluation of morphological indicators of magma supply and segmentation from a seismic reflection study of the East Pacific Rise $15^{\circ} 30^{\prime}-17^{\circ} \mathrm{N}, J$. Geophys. Res., 105, 2737-2759.
Carlut, J., and D. V. Kent (2000), Paleointensity record in zero-age submarine basalt glasses: Testing a new dating technique for recent MORBs, Earth Planet. Sci. Lett., 183, 389-401.

Carlut, J., and D. V. Kent (2002), Grain-size-dependent paleointensity results from very recent mid-oceanic ridge basalts, J. Geophys. Res., 107(B3), 2049, doi:10.1029/2001JB000439.

Carlut, J., J.-P. Valet, X. Quidelleur, V. Courtillot, T. Kidane, Y. Gallet, and P.-Y. Gillot (1999), Paleointensity across the Reunion Event in Ethiopia., Earth Planet. Sci. Lett., 170, 17-34.

Champion, D. (1980), Holocene geomagnetic secular variation in the western United States: Implications for the global geomagnetic field, Ph.D. thesis, 311 p., Calif. Inst. of Technol., Pasadena, Calif.

Chauvin, A., R. A. Duncan, N. Bonhommet, and S. Levi (1989), Paleointensity of the Earth's magnetic field and K-Ar dating of the Louchadiere volcanic flow (central France): New evidence for the Laschamp Excursion, Geophys. Res. Lett., 16, 1189-1192.

Christie, D. M. (1994), Dating the young ocean floor, Nature, 367, $114-$ 115.

Cleveland, W. S. (1979), Robust locally weighted regression and smoothing scatter plots, J. Am. Stat. Assoc., 74(368), 829-836.

Coe, R. S. (1967), Paleointensities of the Earth's magnetic field determined from Tertiary and Quaternary rocks, J. Geophys. Res., 72, 3247-3262.

Coe, R. S., S. Grommé, and E. A. Mankinen (1978), Geomagnetic paleointensities from radiocarbon-dated lava flows on Hawaii and the question of the Pacific nondipole low, J. Geophys. Res., 83, 1740-1756.

Crisp, J. A. (1984), Rates of magma emplacement and volcanic output, J. Volcanol. Geotherm. Res., 20, 177-211.

Dekov, V. M., and V. M. Kuptsov (1992), Late Quaternary rates of accumulation of metal-bearing sediments on the East Pacific Rise, Oceanology, 32, 94-101.

DeMets, C., R. G. Gordon, D. F. Argus, and S. Stein (1994), Effect of recent revisions to the geomagnetic reversal timescale on estimates of current plate motions, Geophys. Res. Lett., 21, 2191-2194.

Donnelly, K. E. (2002), The genesis of E-MORBS: Extensions and limitations of the hot spot model, Ph.D. thesis, 251 pp., Columbia Univ., N. Y. Embley, R. W., J. E. Lupton, G. J. Massoth, T. Urabe, V. Tunnicliffe, D. A. Butterfield, T. Shibata, O. Okano, M. Kinoshita, and K. Fujioka (1998), Geological, chemical, and biological evidence for recent volcanism at 17. $5^{\circ}$ S: East Pacific Rise, Earth Planet. Sci. Lett., 163, 131-147.

Gee, J. S., and D. V. Kent (1998), Magnetic telechemistry and magmatic segmentation on the southern East Pacific Rise, Earth Planet. Sci. Lett., 164, 379-385.

Gee, J. S., S. C. Cande, J. A. Hildebrand, K. E. Donnelly, and R. L. Parker (2000), Geomagnetic intensity variations over the past $780 \mathrm{kyr}$ obtained from near-seafloor magnetic anomalies, Nature, 408, 827-832.

Gillot, P. Y., C. Labeyrie, C. Laj, G. Valladas, G. Guerin, G. Poupeau, and G. Delibrias (1979), Age of the Laschamp paleomagnetic excursion revisited, Earth Planet. Sci. Lett., 42, 444-450.

Goldstein, S. J., M. T. Murrell, D. L. Janecky, J. R. Delaney, and D. A. Clague (1991), Geochronology and petrogenesis of MORB from the Juan de Fuca and Gorda ridges by 238U-230Th disequilibrium, Earth Planet. Sci. Lett., 107, 25-41.

Goldstein, S. J., M. R. Perfit, R. Batiza, D. J. Fornari, and M. T. Murrell (1994), Off-axis volcanism at the East Pacific Rise detected by uraniumseries dating of basalts, Nature, 367, 157-159.

Guyodo, Y., and J.-P. Valet (1999), Global changes in intensity of the Earth's magnetic field during the past $800 \mathrm{kyr}$, Nature, 399, 249-252.

Haymon, R. M., et al. (1993), Volcanic eruption of the mid-ocean ridge along the East Pacific Rise at $9^{\circ} 45^{\prime}-52^{\prime} \mathrm{N}$ : Direct submersible observations of seafloor phenomena associated with an eruption event in April, 1991, Earth Planet. Sci. Lett., 119, 85-101.

Heller, R., R. T. Merrill, and P. L. McFadden (2002), The variation of intensity of Earth's magnetic field with time, Phys. Earth Planet. Inter, 131, 237-249.

Hulot, G., C. Eymin, B. Langlais, M. Mandea, and N. Olsen (2002), Smallscale structure of the geodynamo inferred from Oersted and Magsat satellite data, Nature, 416, 620-623.

Jackson, A., A. Jonkers, and M. R. Walker (2000), Four centuries of geomagnetic Secular variation from historical records, Philos. Trans. R. Soc. London, Ser. A, 358, 957-990.

Karson, J. A., S. D. Hurst, and P. F. Lonsdale (1992), Tectonic rotations of dikes in fast-spreading oceanic crust exposed near Hess Deep, Geology, 20, 685-688.

Kent, D. V., and J. S. Gee (1996), Magnetic alteration of zero-age oceanic basalt, Geology, 24, 703-706.

Kent, D. V., S. R. Hemming, and B. D. Turrin (2002), Laschamp Excursion at Mono Lake?, Earth Planet. Sci. Lett., 197, 151-164.

Langmuir, C. H., J. F. Bender, and R. Batiza (1986), Petrological and tectonic segmentation of the East Pacific Rise, $5^{\circ} 30^{\prime}-14^{\circ} 30^{\prime} \mathrm{N}$, Nature, $322,422-429$. 
Langmuir, C. H., J. Bender, K. Donnelly, S. Shirey, M.-H. Cormier, and E. Baker (1998), Petrology of the East Pacific Rise north of the Orozco transform fault, Eos Trans. $A G U, 79(45)$, Fall Meet. Suppl., F832.

Le Goff, M., Y. Gallet, A. Genevey, and N. Warmé (2002), On archeomagnetic secular variation curves and archeomagnetic dating, Phys. Earth Planet. Inter, 134, 203-211.

Macdonald, K. C. (1998), Linkage between faulting, volcanism, hydrothermal activity and segmentation on fast spreading centers, in Faulting and Magmatism at Mid-Ocean Ridges, Geophys. Monogr. Ser., vol. 106, edited by W. R. Buck et al., pp 27-58, AGU, Washington, D. C.

Macdonald, K. C., J.-C. Sempéré, P. J. Fox, and R. Tyce (1987), Tectonic evolution of ridge-axis discontinuities by the meeting, linking, or self-decapitation of neighboring ridge segments, Geology, 15, 993997.

Macdonald, K. C., R. M. Haymon, and S. P. Miller (1988), Deep-tow and Sea Beam studies of dueling propagating ridges on the East Pacific Rise near $20^{\circ} 40^{\prime} \mathrm{S}$, J. Geophys. Res., 93, 2875-2898.

Macdonald, K. C., et al. (1992), The East Pacific Rise and its flanks $8^{\circ}-$ $18^{\circ} \mathrm{N}$ : History of segmentation, propagation and spreading direction based on SeaMarc II and SeaBeam studies, Mar. Geophys. Res., 14, 299-344.

MacLeod, C. J., and D. A. Rothery (1992), Ridge axial segmentation in the Oman ophiolite: Evidence from along-strike variations in the sheeted dike complex, in Ophiolite and Their Modern Oceanic Analogues, edited by L. M. Parson, B. J. Murton, and P. Browning, Geol. Soc. Spec. Publ., 60 , $39-63$.

Mankinen, D. A., and D. E. Champion (1993), Latest Pleistocene and Holocene geomagnetic paleointensity on Hawaii, Science, 262, $412-416$.

Marchig, V., J. Erzinger, and P. M. Heinze (1986), Sediment in the black smoker area of the East Pacific Rise $\left(18.5^{\circ} \mathrm{S}\right)$, Earth Planet. Sci. Lett., 79 , 93-106.

McElhinny, M. W., and P. L. McFadden (2000), Paleomagnetism: Continents and Oceans, Int. Geophys. Ser., vol. 73, 386 pp., Academic, San Diego, Calif.

McElhinny, M. W., and W. E. Senanayake (1982), Variations in the geomagnetic dipole 1: The past 50,000 years, J. Geomagn. Geoelectr., $34,39-51$

Mejia, V., N. D. Opdyke, and M. R. Perfit (1996), Paleomagnetic field intensity recorded in submarine basaltic glass from the East Pacific Rise, the last $69 \mathrm{Ka}$, Geophys. Res. Lett., 23, 475-478.

Milligan, B. N., and V. Tunnicliffe (1994), Vent and nonvent faunas of Cleft segment, Juan de Fuca Ridge, and their relations to lava age, J. Geophys. Res., 99, 4777-4786.

Perrin, M., E. Schnepp, and V. Shcherbakov (1998), Paleointensity database updated, Eos Trans. AGU, 79(16), 198.

Pick, T., and L. Tauxe (1993), Holocene paleointensities: Thellier experiments on submarine basaltic glass from the East Pacific Rise, J. Geophys Res., 98, 17,949-17,964

Pick, T., and L. Tauxe (1994), Characteristics of magnetite in submarine basaltic glass, Geophys. J. Int., 119, 116-128.

Rubin, K. H., J. D. Macdougall, and M. R. Perfit (1994), 210Po-210Pb dating of recent volcanic eruptions on the sea floor, Nature, 368, 841844
Rubin, K. H., M. C. Smith, M. R. Perfit, D. M. Christie, and L. F. Sacks (1998), Geochronology and geochemistry of lavas from the 1996 North Gorda Ridge eruption, Deep Sea Res., Part II, 45, 2571-2597.

Scheirer, D. S., and K. C. Macdonald (1993), Variations in cross-sectional area of the axial ridge along the East Pacific Rise: Evidence for the magmatic budget of a fast spreading center, J. Geophys. Res, 98, $7871-7885$.

Sempéré, J.-C. (1991), High magnetization zones near spreading center discontinuities, Earth Planet. Sci. Lett., 107, 389-405.

Sinton, J. M., E. C. Bergmanis, K. H. Rubin, R. Batiza, T. K. P. Gregg, K. Grönvold, K. C. Macdonald, and S. M. White (2002), Volcanic eruptions on mid-ocean ridges: New evidence from the superfast spreading East Pacific Rise, $17^{\circ}-19^{\circ} \mathrm{S}$, J. Geophys. Res., 107(B6), 2115, doi:10.1029/2000JB000090.

Smirnov, A. V., and J. A. Tarduno (2003), Magnetic hysteresis monitoring of Cretaceous submarine basaltic glass during Thellier paleointensity experiments: Evidence for alteration and attendant low field bias, Earth Planet. Sci. Lett., 206, 571-585.

Sternberg, R., and R. McGuire (1990), Techniques for constructing secular variation curves and for interpreting archaeomagnetic dates, in Archeomagnetic Dating, edited by J. Eighmy and R. Sternberg, pp. 109134, Univ. of Ariz., Tucson.

Tauxe, L., and J. J. Love (2003), Paleointensity in Hawaiian Scientific Drilling Project Hole (HSDP2): Results from submarine basaltic glass, Geochem. Geophys. Geosyst., 4(2), 8702, doi:10.1029/2001GC000276.

Tivey, M. A., H. P. Johnson, A. Bradley, and D. Yoerger (1998), Thickness of a submarine lava flow determined from near-bottom magnetic field mapping by autonomous underwater vehicle, Geophys. Res. Lett., 25, $805-808$

Valet, J. P., E. Tric, E. Herrero-Bervera, L. Meynadier, and J. P. Lockwood (1998), Absolute paleointensity from Hawaiian lavas younger than $35 \mathrm{ka}$, Earth Planet. Sci. Lett., 161, 19-32.

Weiland, C. M., and K. C. Macdonald (1996), Geophysical study of the East Pacific Rise $15^{\circ} \mathrm{N}-17^{\circ} \mathrm{N}$ : An unusually robust segment, J. Geophys. Res., 101, 20,257-20,273.

Wessel, P., and W. H. F. Smith (1998), New, improved version of the Generic Mapping Tools released, Eos Trans. AGU, 79(47), 579. [version 3.1]

Yang, S., H. Odah, and J. Shaw (2000), Variations in the geomagnetic dipole moment over the last 12,000 years, Geophys. J. Int., 140, 158-162.

Yu, Y., D. J. Dunlop, L. Pavlish, and M. Cooper (2000), Archeomagnetism of Ontario potsherds from the last 2000 years, J. Geophys. Res., 105, $19,419-19,433$

Zhou, W., R. Van der Voo, and D. R. Peacor (1999), Preservation of pristine titanomagnetite in older ocean-floor basalts and its significance for paleointensity studies, Geology, 27, 1043-1046.

J. Carlut, Lamont-Doherty Earth Observatory, Columbia University, Route 9W, Palisades, NY 10964, USA. (jcarlut@geologie.ens.fr)

M.-H. Cormier, K. E. Donnelly, and D. V. Kent, Lamont-Doherty Earth Observatory, Columbia University, Route 9W, Palisades, NY 10964, USA.

C. H. Langmuir, Department of Earth and Planetary Sciences, Harvard University, 20 Oxford Street, Cambridge, MA 02138, USA. 